\title{
Etat actuel de la question des Sporotrichoses.
}

\section{Les progrès accomplis. - Les discussions botaniques. Intérêt pratique, pronostique, thérapeutique et économique. Intérêt dootrinal des Sporotrichoses.}

\author{
Par \\ de Beurmann, \\ Médecin de l'Hôpital Saint-Louis \\ de Paris. \\ et \\ Professeur agrégé à la Faculté de Mé. \\ decine de Paris.
}

Bien que l'histoire des Sporotrichoses ne date que de quelques années, leur étude est aujourd'hui presqu' achevée. ${ }^{\mathbf{1}}$ ) Il est donc facile de résumer en quelques pages l'état actuel de la question, de marquer les progrès accomplis, de signaler les points qui restent en discussion et de montrer le double intérêt pratique et doctrinal de ces mycoses.

I.

\section{Les progrès accomplis.}

On donne le nom les Sporotrichoses à des infections communes à l'homme et aux animaux, dues à des champignons filamenteux et sporulés du genre Sporotrichum: Sporotrichum Schencki, Sporotrichum Beurmanni (et ses variétés: Sporotrichum Beurmanni, variêté asteroïdes, Sporotrichum Beurmanni, variété indicum), Sporotrichum Jeanselmei, Sporotrichum Gougeroti, Sporotrichum

1) L'étude complète détaillée des Sporotrichoses est faite dans notre livre: de Beurmann et Gougerot, Les Sporotrichoses, F. A l can et Lisbonne Editeurs, Paris 1911. De nombreux emprunts ont été faits au chapitre Historique de ce livre pour le présent article. 
Dori, chaque parasite servant à définir une sporotrichose du même nom. Il n'y a donc pas une Sporotrichose, mais des Sporotrichoses.*

L'histoire des Sporotrichoses est toute récente; ${ }^{\mathbf{1}}$ ) leur nom n'existait même pas dans la nosologie il y a quelques années. Jusq'à notre premier Mémoire de $1906,{ }^{2}$ ) les Sporotrichoses étaient ignorées ou méconnues; notre étude d'ensemble, réunissait les rares documents publiés jusque-là, et faisait le premier connaître ces mycoses. Il en disting aait trois variétés.

Lı première variété est la Sporotrichose de Schenck, due à un parasite cultivé par Schenck aux Etats-Unis d'Amérique, étudié et catalogué Sporotrichum par Smith (1898), appelé par Hektoen et Perkins Sporothrix Schencki (1900), nom que nous avons corrigé en celui de Sporotrichum Schencki (1906). La Sporotrichose de Schenck n'a été connue jusqu'en 1909 que par les deux observations américaines, celle de Schenck (1898) et celle d'HektoenPerkins (1900). Ce n'est que par analogie clinique qu'Hektoen-Perkins ont assimilé à leur cas un fait clinique de Brayton, auquel manque le contrôle histologique. Dans ces deux (ou trois) cas nord-américains, la Sporotrichose de Schenck, inoculée par une blessure du doigt, avait la forme d'une lymphangite gommeuse ascendante du bras, comparable aux lymphangites tuberculo-bacillaires (type Schenck). Cette forme est lente à guérir et l'iodure semble moins actif contre elle que contre la Sporotrichose de de Beurmann. Ces faits nord-américains étaient complètement ignorés en

1) Parmi les parasites anciennement décrits sous d'antres noms ou restés innommés, il en est peut-être que l'on rattacherait aujourd'hui au genre Sporotrichum. I faut se demander par exemple si la belle observation d'abcès lymphangitique du bras chez un diabétique, rapportée par A ucher et Le Dantec, n'est pas une sporotrichose, si le parasite cultivé dans ce cas et catalogué par Fayod sous le nom de Bothrytis pyogenes n'est pas un Sporotrichum voisin du Sporotrichum Beur. mani.

2) De Beurmann et Gougerot. Les Sporotrichoses hypodermiques. Annal. de Dermat. et de Syphil. 1906 oct., nov., déc., p. $887,914,993$. 
Europe, bien que Foulerton, en 1901, eût donné à la Pa. thological Society of London une excellente étude du iSporothrix Schencki<. Les premiers, en 1906, nous avons résumé ces travaux et nous les arons fait connaître en France. Dans l'Amérique du Nord les deux cas de Schenck et d'Hektoen-Perkins restèrent isolés jusqu'en 1909. L'heureuse fortune du Sporotrichum Beurmanni les tira de l'oubli et grâce au mouvement que nos travaux ont suscité de toutes parts, des cas nouveaux de Sporotrichose de l'homme et. du cheval ont été découverts en 1909 et 1910 par Burlew, par Trimble et Shaw, par Page, Frothingham et Paige, par Mohler, par J. N. Hyde et Davis, aux Etats-Unis, et par Duque à Cuba. Ces auteurs, identifient leurs parasites au Sporotrichum Schencki, et rangent leurs observations dans la Sporotrichose de Schenck; leurs derniers travaux remettent en discussion les affinités du Sporotrichum Schencki et du Sporotrichum Beurmani.

La deuxi ème variété est la Sporotrichose de de Beurmann, due à un parasite découvert à l'Hôpital Saint-Louis par de. Beurmann et Ramond (1903), cultivé dans le laboratoire de Sabouraud, identifié et catalogué Sporotrichum Beurmanni par Matruchot et Ramond (1905) dans une note présentée à la Société de Biologie. Cette sporotrichose, que nos travaux. de 1906 et des années suivantes, confirmés par tous les auteurs français et étrangers ont démontrée la fréquence et le polymorphisme, n'était connue avant 1906 que par l'observation princeps de de Beurmann et $R$ amand. La mycose revêtait dans ce premier cas de 1903 la forme de gommes sous-cutanées. disséminées non ulcéreuses (type de Beurmann). Le malade était atteint de tumeurs * hypodermiques multiples rénitentes et le diagnostic le plus probable semblait être celui de ladrerie. Cette conclusion ne nous paraissant pas plus satisfaisante qu'aucun des diagnostics proposés, plusieurs des tumeurs furent incisées ou excisées et la recherche de tous les agents pathogènes conuus ayant été négative, le pus fut ensemencé sur toutes sortes de milieux, entre autres sur les milieux d'épreuve de Sabouraud dont le laboratoire nous était libéralement 
ouvert. Ces tubes, mis à l'étuve à $37^{\circ}$, donnèrent les premières cultures du champignon qui fut décrit et identifié par Matruchot et Ramond. C'est l'observation de ce premier malade qui nous montra l'efficacité du traitement ioduré général qui lui avait été administré par analogie avec celui des actinomycoses.

La troisième variété et la Sporotrichose de Dor, due à un parasite cultivé, étudié et catalogué Sporotrichum par Dor à Lyon $(1906)^{1}$ ) et dénommée par nous Sporotrichum Dori (1906), parasite très-différent du Sporotrichum Beurmanni et du Sporotrichum Schencki. ${ }^{2}$ ) Cette mycose n'est connue que par l'unique observation de Dor: sporotrichose sub-aiguë à grands abcès à répétition.

En résumé, au début de 1906, on comptait deux observations de Sporotrichose de Schenck, une observation de Sporotrichose de de Beurmann, une observation de Sporotrichose de Dor. Ces faits isolés avaient passé inaperçus; ${ }^{3}$ ) leur importance avait été méconnue; ils n'avaient pas créé un mouvement et restaient ignorés. Si quelques spécialistes, dont la bibliographie ne laisse rien échapper, avaient eu connaissance de ces observations, ils les rangeaient parmi ces raretés sans importance pratique qui encombrent la dermatologie.

1) C'est dans le titre de cette observation de Dor que l'on trouve imprimée pour la première fois le nom de Sporotrichose.

2) La détermination Sporotrichum qui a été faite par Dor et que nous adoptons jusqu'à classification meilleure, peut être discutée, car le parasite de Dor ne présente pas tous les caracières des Sporotrichum tels que Linck les définit. Peut-être ce parasite, en raison de ses ressemblances avec l'Oospora de Nocard, mériterait-il d'être appelé Oospora ou Discomyces Dori.

s) Il suffit, pour le démontrer, de citer ce passage de Lutz et Splendore, écrit en 1907: snous pensions avoir rencontré des cas absolument nouveaux car nous n'avions pu trouver dans la littérature rien de semblable ..... et quand l'un de nous, il y a deux ans, montra dans différents centres scientifiques d'Europe ses préparations microscopiques et anatomiques ainsi que des cultures, il ne parvint pas à apprendre quelquechose au sujet de processus semblables. Ni à l'Institut Pasteur, ni à ceux de Plaut, de Buschke, de Curtis..., ce champignon ni des champignons semblables n'étaient connuss. 
Ce fut l'œurre de notre premier Mémoire de 1906 de coordonner ces faits épars, de les éclairer par des faits nouveaux que nous avions suivis et de mettre en lumière dans une étude nouvelle la question des Sporotrichoses. Notre travail faisait connaître les travaux américains de Schenck, d'Hektoen-Perkins; il inaugurait l'étude de la Sporotrichose de de Beurmann qui semble maintenant englober toute la Sporotrichose.

1906-mars 1907. C'est de notre premier Mémoire de 1906 que datent la notion de la fréquence des sporotrichoses et l'essor qu'a pris leur étuder. Ce travail ${ }^{1}$ ) dont Ravaut a dit qu'il srestera le mémoire fondamental de cette question des Sporotrichoses*, étudiait ces mycoses dans tous leurs chapîtres.

Basé sur deux observations nouvelles ${ }^{2}$ ) (No. II et No. III), il en prévoyait la fréquence. Il individualisait la plus commune de leurs formes cliniques: la sporotrichose gommeuse disséminée et il en décrivait les trois aspects symptomatiques. Il séparait ces mycoses de la syphilis avec lesquelles on les arait toujours confondues. Il indiquait déjà les caractères qui peuvent faire soupçonner la maladie et qui, chez notre troisième malade, avait permis d'affirmer cliniquement, avant la culture, le diagnostic de Sporotrichose, à la consultation de l'Bôpital SaintLouis. Il mettait en lumière "les petits signes * de ce diagnostic qui allait bientôt s'enrichir d'éléments nouveaux: le *nombre des nodosités, disions-nous, dépasse d'ordinaire cinq, chiffre qu'atteint rarement la syphilis gommeuse non ulcérée; les gommes sont d'âges très différents, les unes encore indurées,

1) Ces premières études furent poursuivies dans le laboratoire de de Beurmann, dans celui de Sabouraud, à l'Hôpital Saint-Louis.

2) La découverte de ce cas No. II fut faite grâce à l'étude systématique d'un cas de diagnostic difficile (voir ci-dessous).

Le cas No. II nous montra toute l'importance du diagnostic bactériologique et nous prouva tous les avantages de la culture à froid sur gélose glycosée peptonée (voir ci-dessous note).

Notre attention étant attirée sur la Sporotrichose bientôt nous trouvions un troisième cas. Nous avons diagnostiqué cliniquement ce cas No. III, avant la culture, que Noiré fit obligeamment daus le laboratoire de Sabouraud. 
les autres en roie de ramollissement, d'autres abcédées; leur évolution rapide est complète en six à huit semaines; le ramollissement se fait sans poussée inflammatoire douloureuse. La peau rosit à peine et dans cette forme non-ulcéreuse, elle ne contracte que quelques adhérences avec l'abcès sous-jacent. La lésion abcédée atteint et dépasse souvent le volume d'une noix; elle contient un pus visqueux ou du séro-pus fluide, mais pas de bourbillon; l'ouverture se cicatrise souvent malgré la persistance de la poche purulente*.

La culture nous paraissait le seul moyen d'assurer le diagnostic et les premiers nous indiquions le procédé diagnostique si simple, aujourd'hui classique et partout adopté, de la culture à froid du pus sur gélose-glycosée peptonée de Sabouraud, sans capuchonnage des tubes. Ce procédé de la culture à froid, technique générale, qui, on le sait, a été réglée par Sabouraud pour la culture des teignes a été désignée par Ravaut sous le nom de »méthode de de Beurmann et Gougerot«, nom adopté à sa suite par les auteurs français et étrangers. En effet, dans les cas nord-américains de 1898 - 1900, dans le cas No. I de 1903, les tubes initiaux avaient été mis à l'étuve à $37^{0}$ ) ) et c'est notre cas No. II (1906) qui nous a révélé l'importance de la culture à froid. ${ }^{2}$ )

Nous n'arons pas cessé depuis de montrer la simplicité de cette méthode de diagnostic; la culture, en effet, ne réclame

1) Voir Annal. de Dermat. et de Syph. 1903, p. 680 et 682.

2) A propos de ce cas No. II, on discutait les diagnostios de syphilis gommeuse et de tuberculose atypique (sarcoïde) et l'on ne pensait pas à la Sporotrichose. L'un de nous, dans un travail d'ensemble sur les bacillo-tuberculoses non folliculaires, poursuivit par tous les procédés en usage l'étude des cas qui pouvaient rentrer dans ce cadre. Afin de faire l'examen bistologique et l'inoculation, il pratiqua l'ablation d'une gomme du tronc dans le laboratoire du service du Docteur de Beur. mann (laboratoire $\mathrm{C} a \mathrm{z} \in \mathbf{n} \mathrm{a} v \mathrm{e}$ ). Incisant cette gomme qu'il ne croyait pas ramollie, il fut étonné de trouver au centre quelques gouttes de pus visqueux; il les ensemença immédiatement dans la salle-même où aqait lieu la petite opération. Il prit le premier milieu qui se trouva sous sa. main et qui, par un heureux hasard, était de la gélose glycosée peptonée de Sabouraud, destinée à ensemencer des teignes. Ce premier ensemencement fut donc fait sans idée préconçue. 
ni laboratoire, puisque les tubes sont laissés à la température ordinaire, ni microscope, puisque l'aspect macroscopique des colonies blanches puis brunes est plus caractéristique que le frottis microscopique. En cinq à huit jours, elle affirme le diagnostic par une épreuve si simple, qu'elle peut être faite dans une salle d'hôpital ou dans le cabinet de consultation du médecin et ne demande que quelques minutes. Nous montrions que la culture est le seul procédé de diagnostic pratique, tandis que la recherche du parasite dans les frottis de pus et les inoculations sont aléatoires.

Nous complétions la description parasitologique et morphologique du champignon que Matruchot et Ramond avaient si bien précisée, nous étudiions sa structure fine, sa sporulation, ses chlamydospores, etc. ...; nous inventions la »technique des lames sèches*, procédé si commode pour l'identification et pour l'étude microscopique des parasites; nous indiquions les principaux caractères biologiques du parasite. Nous discutions la classification botanique et l'anatomie des sporotrichum, champignons filamenteux à spores externes, auxquels l'absence de forme parfaite de reproduction ne permet pas de donner une place définitive dans la flore botanique; mais nous insistions sur ce fait que le Sporotrichum Beurmanni est un parasite sdéterminé par des caractères précis et toujours identiques à eux-mêmes, créant des lésions du même ordre, et c'est, ajoutions-nous, ce qui importe le plus. \&

Nous donnions, en nous inspirant de l'enseignement histologique de Dominici, la description anatomique et histolo-

Laissant quelques tubes à l'étuve, d'autres à froid̄, il vit que les tubes laissés à la température ordinaire poussaient abondamment, alors qu'au contraire les tubes mis à l'étuve à $37^{\circ}$ ne fructifiaient pas ou plutôt ne donnaient des cultures qu'après avoir été sortis de l'étuve. Ce fait le frappa vivement. Les jours suivants, les ensemencements du pus des autres gommes, suivis en séries parallèles à $37^{0}$ et à froid, affirmèrent l'exactitude de cette première remarque que tous les auteurs ont confirmée et qui a servi à établir la méthode de diagnostic aujourd'hui universellement adoptée. On voit donc que c'est l'étude systématique d'un cas catalogué syphilis ou sarcoide tuberculeuse qui permit de retrouver la Sporotrichose de de Beurmann dont l'importance était alors insoupçonné. 
gique de la gomme hypodermique. Nous dégagions la formule histologique des sporotrichomes nodulaires, leur ordination en trois zones: micro-abcès central à polynucléaires et à macrophages, zone épithélioïde et giganto-cellulaire moyenne, zone lympho-conjonctive ou fibro-cellulaire externe, et nous insistions sur le mélange si caractéristique de ces trois réactions: ecthymatiforme, tuberculoïde, syphiloïde. Nous donnions la formule cytologique du pus sporotrichosique: polynucléaires et macrophages peu avariés. Nous décrivions enfin la forme courte-oblongue que prend le parasite dans les lésions humaines et expérimentales, montrant qu'il ne s'agit pas d'une spore, comme l'avaient cru les auteurs américains pour le Sporotrichum Schencki, mais d'une forme courte mycélienne adaptée à la vie parasitaire.

Nos observations étaient contrôlées et affirmées par l'expérimentation: nous citions en effet les premières inoculations au rat et les deux premiers cas de reproduction de gommes sous-cutanées métastatiques généralisées obtenues chez le cobaye noureau-né par l'inoculation sous-cutanée de cultures pures; la constatation des formes parasitaires dans les tissus et les rétracultures ne laissaient aucun doute sur l'authenticité de ces lésions du rat et du cobaye. Ces sporotrichoses expérimentales étaient d'une importance capitale; car, non seulement elles prouvaient la virulence du germe retiré des lésions humaines, mais elles reproduisaient la maladie humaine caractérisée par des gommes sous-cutanées, d'abord indurées, puis secondairement abcédées. Résumant cette étude expérimentale, nous attirions l'attention sur la faible virulence du Sporotrichum Beurmanni.

Nous nous attachions à l'étude du problème pathogénique et étiologique; nous en posions les principaux points et nous résolvions plusieurs d'entre eux. La porte d'entrée nous échappait, mais par toute une série de cultures sur les milieux végétaux naturels et sur les insectes, nous affirmions le saprophytisme du Sporotrichum Beurmanni dans la nature que confirma plus tard la déconverte du Sporotrichum sauvage par l'un de nous, en deux points des Alpes françaises. Nous énumérions les nombreux intermédiaires qui deraient trans- 
mettre la mycose à l'homme: débris végétaux, graines, fruits; etc. nous prouvions la possibilité de la porte d'entrée cutanée en obtenant chez deux cobayes noureau-nés, par inoculation sous-cutanée de cultures pures, la gomme métastatique qui reproduit la maladie humaine. Nous concluions que le germe *se rencontre dans le milieu ambiant où il vit en saprophyte, qu'il est inoculé par l'intermédiaire des végétaux et des animaux et qu'il se dissémine ultérieurement dans l'organisme par la voie artérielle". Nous prouvions expérimentalement la possibilité du saprophytisme sur la peau et dans les cavités muqueuses et guidés par ces faits expérimentaux, nous suspections déjà l'infection par la voie gastro-intestinale alimentaire, c'est-à-dire l'inoculation de sporotrichum déglutis avec des aliments parasités que nous avons démontrée en 1907 dans notre troisième Mémoire.

Enfin nous montrions les excellents effets du traitement ioduré général et nous recommandions le traitement iodo-ioduré local. Nous insistions sur l'importance pronostique et thérapeutique du diagnostic de Sporotrichose qui délivre les malades de la menace de deux maladies des plus graves, la syphilis et la tuberculose.

En résumé, ce premier mémoire séparait $\gg$ du groupe des gommes et des abcès sous-cutanés multiples une des principales formes des Sporotrichoses et rien ne manquait à cette individualisation, même pas la reproduction expérimentale de la maladie".

Notre premier Mémoire était immédiatement complété par une étude comparative des mycoses voisines et de la Sporotrichose ${ }^{1}$ ) et par une étude diagnostique arec parallèle clinique, diagnostique, bactériologique, anatomique, pronostique et thérapeutique de cette mycose et de la syphilis. ${ }^{2}$ )

Nos premiers travaux de 1906 embrassaient done l'ensemble des Sporotrichoses et comprenaient leur étude clinique et dia-

1) Gougerot. Mycoses sous-cutanées. Trib. méd. 26 janv. et 2 fév. 1907. No. 4 et No. 5.

2) Gougerot. Diagnostic de la syphilis et des Sporotrichoses. Ann. des Malad. vénér. 1 mars 1907, p. 161. 
gnostique, botanique et parasitologique, anatomique, histologique et expérimentale, étiologique et pathogénique, pronostique et thérapeutique.

1907. - Le 3 janvier 1907, nous développions devant la Société de Dermatologie ${ }^{1}$ ) le résultat de ces recherches originales et nous présentions les documents, les cultures, les pièces humaines et expérimentales qui avaient servi à l'édification de notre mémoire.

Le même jour, nous montrions avec Danlos et Deroye notre troisième malade ${ }^{2}$ ) et nous décrivions les premiers cas de gros abcès et de lymphangite sporotrichosique, de sporotrichoside dermique ${ }^{3}$ ) qui: "simulent l'ecthyma et souvent ressemblent plus ou moins à la syphilis papulocrustacée, voire même aux tuberculides papulo-squameuses ou à l'érythème induré de $\mathrm{B}$ azin ulcéré *. Nous individualisions aussi la forme mixte de la Sporotrichose. Le 7 mars, à la même Société, en présentant notre quatrième malade, nous décrivions le premier cas de sporotrichose gommeuse ulcéreuse. "La plnpart des lésions dispersées sans aucune systématisation, disions-nous, sont ouvertes. On voit autour d'un orifice étroit une zone ovalaire dans laquelle la peau amincie et violacée recourre une dépression sous-cutanée appréciable au doigt; l'ensemble de la lésion reproduit exactement l'aspect de la gomme tuberculeuse ouverte et ce diagnostic a été admis à première vue à la consultation. ${ }^{4}$ )

Telles étaient nos premières recherches, basées sur quatre cas personnels, les seuls alors connus de Sporotrichose de de Beurmann.

* Ces premières études ont été confirmées par tous les auteurs et, si quelques-uns omettent de les citer, la plupart leur ont rendu justice. E Elles fondaient sur des preuves irréfutables l'autonomie de la sporotrichose: cultures pures de lésions fermées, donnant chez tous les malades, dans toutes les

1) Bull. de la Soc. de Derm. et de Syphil, 3 janv. 1907. p. 22.

2) loco cit., p. 19.

s) loco cit., p. 26.

4) loco cit., p. 84 . 
lésions, à plusieurs jours d'intervalle et sur tous les ensemencements, toujours le même parasite; présence dans les lésions de la forme courte du parasite; formule histologique spéciale; reproduction expérimentale de la gomme métastatique; guérison rapide par le traitement ioduré. Aujourd'hui ces preuves sont incontestées, mais il était alors nécessaire de les rassembler pour vaincre l'incrédulité générale, car beaucoup de nos collègues, surpris par la nouveauté de nos recherches, regrettaient de nous voir stoucher par un sacrilége imprudent à ces deux arches saintes de la Dermatologie: la Syphilis et la Tuberculose.

Mars 1907 - Décembre 1907. A la suite de nos quatre premiers cas de Sporotrichose, les observations ne tardèrent pas à s'aćcumuler. De toutes parts nos travaux furent confirmés par de nombreux auteurs français et étrangers qui retrouvèrent le $\mathrm{Sp}$ or o trichum $\mathrm{Beurmanni}$ et complétèrent nos études: Danlos et Deroye, Lesné et MonierVinard, Gaucher, Brocq, Dural et Fage, Vaquez, Laubry et Esmein, Demoulin, Dominici, Ravaut et Civatte, Brissaud et Rathery, Nattan-Larier et Gastou et Brodier, Loeper, Bonnet, Lutz et Splendore au Brésil, P. Baliña et Marco del Pont en Argentine, Greco en Uruguay, Blanc, de Massary et Doury, Letulle et Debré, Louste, Balzer et Galupe, Fouquet et Giroux, Caraven, Sicard et Bith, Druelle et Chadzinski, Hudelo, Widal et Weill, Morax et Carlotti, Descomps, Achard, Milian, Spillmann et Gruyer à Nancy, Abrami et Giroux, Gy, Joltrain, Josset-Moure, Boisseau et Fulconis à Nice, Carougeau à Madagascar, Thibierge et Gastinel, Trémolières et Du Castel, Maurice La Goutte et Briau au Creusot, Lerat à Bruxelles, Bruno Bloch à Bâle, Pierre Marie, Jadassohn et Robert Stein à Berne, Castellani à Ceylan, Laroche, Vernes, Verdun, Pautrier et Lutembacher, Lebar et Saint-Girons, Rochard et Bodolec, Rouslacroix, Wyse-Lauzun et Perrin à Marseille, Lindemberg à São Paulo, Du Bois à Genève, o. Krenn et Schrameck à Vienne, Rispal et Dalous, Rouvière à Toulouse, Arndt et Fielitz à Berlin; Cam- 
pana à Rome; Posada Berrio à Medellin (Colombie), E. de Oyarzabal à Madrid; Wolf et Hügel à Strassbourg; C. Vignolo Lutati, Curcio, Carrucio à Rome; Boureau à Tours; $\mathrm{Peugniez}$ et $\mathrm{B}$ ax à Amiens, Dind à Lausanne; Henry à la Guyane; Ségu in à Hanoï; Sabrazès et Guyot, Dubreuilh; Petges et Boni à Bordeaux etc. etc. ...

Danlos et Deroye, ${ }^{1}$ ) Reclus, qui le premier démontra l'existence d'abcès froids non tuberculeux, $\left.{ }^{2}\right)$ Lesné et Monier-Vinard, sont parmi les premiers qui apportèrent des faits semblables. De Beurmann et Gougerot venaient de * publier leur remarquable mémoire basé sur quatre observations personnelles, dit Reclus dans une de ses Cliniques. Notre cas est le cinquième publié en France. Il s'agissait d'un Sporothrix spécial, le Sporothrix de de Beurmann, ansi nommé pour l'opposer au Sporothrix de Schenck et au Sporothrix de Dor, variétés plus rares et un peu différentes.* Lesné et Monier-Vinard, qui avaient déjà parlé à la Société anatomique de ce cas difficile sans pouroir résoudre le problème diagnostique qu'il soulevait, ont fait une étude détaillée de ce cinquième malade devant la Société médjcale des Hopitaux, le 15 mars 1907, et dans un article de la Revue de Médecine, paru en août et en septembre 1907. ${ }^{3}$ )

1) C'est notre malade No. III que, lors d'une récidive, Danlos et Deroye ont étudié en collaboration avec de nous.

2) Au point de vue de l'évolution des idées médicales, il est intéressant de noter quelle fut la pensée directrice du Professeur Reclus. Il cherchait systématiquement à approfondir la nature des abcès froids non tuberculeux. Il posa done dans ce cas No. $V$ le diagnostic d'abcès froid non bacillaires et il dirigea dans ce sens ses élèves Lesné et Monier-Vinard. Ceux-ci furent assez heureux pour isoler le Sporotrichum Beurmanni (Communication orale du Professeur Reclus).

s) En mars 1907, ces auteurs hésitaient sur l'identification de leur champignon: snous ne saurions vraiment dire si notre parasite appartient à l'une de ces trois variétés (Sporotrichum Schencki, Sporotrichum Beurmanni. Sporotrichum Dori) ou s'il forme une variété nouvelle (p. 274). En août et septembre, nne étude approfondie leur permettait de l'identifier au Sporotrichum Beurmanni: sles caractères culturaux et morphologiques sont à peu près identiques, De légères différences peuvent toutefois se relever; nous ne pensons pas qu'elles justifient la création d'une variété nouvelle* ( $p .767$ ). 
Quelques jours après, le 8 avril, à la śociété de Dermatologie ${ }^{1}$ ) et le 12 arril 1907 à la Société Médicale des Hôpitaux de Paris, ${ }^{2}$ nous présentions un sixième malade, premier cas de Sporotrichose gommeuse ulcéreuse syphiloide ou ecthyma sporotrichosique et A. Renault, qui nous avait adressé le malade, faisait ressortir l'intérêt pratique du diagnostic de sporotrichose.

Gaucher montrait à ses Leçons notre malade No. III et deux nouveaux malades, No. VII et No. VIII. Il consacrait deux Cliniques à cette question d'actualité et avec MonierVinard, il montrait le 8 arril, à la Société de Dermatologie, le premier cas de sporotrichose épidermique tricophytoïde. Monier-Vinard présentait ce même cas à la Société médicale des Hôpitaux (No. VII) en même temps qu'une observation nouvelle (cas No. VIII). ${ }^{3}$ )

Dès lors les observations se multipliièent: observation No. IX de Dural et Fage, observation de Laubry et Esmein (No. $X$ avec première autopsie) qui sert de point de départ à la thèse de Peltier intitulée: Sporotrichose gommeuse disséminée, Maladie de de Beurmann (mai 1907). Une note du Journal des Praticiens du 11 mai 1907 insistait sur l'importance pratique de la Sporotrichose. >C'est, disait-il, parce qu'elle est devenue une question de pratique susceptible d'un traitement efficace et simple qu'il importe au praticien de ne pas l'ignorer et de faire bénéficier ses malades de notions si importantes. * ${ }^{4}$ )

1) Bull. de la Soc. de Dermat. et de Syph. p. 12. p. 309.

2) Bull. et Mém. de la Soc. méd. des Hôp. de Paris. Nr. 12;

3) Dans l'une de ces observations, Monier-Vinard ayant constaté du Sporotrichum Beurmanni daus l'expectoration de son malade (tuberculeux dont les crachats contenaient des bacilles de Kooh), a cru pouvoir conclure à une Sporotrichose pulmonaire. Nous avons montré que cette conclusion était prématurée, le Sporotrichum venant sans donte du bucco-pharynx comme dans notre observation No. VI et comme dans ce cas de Laubry et Esmein quí eut le contrôle de l'autopsie.

4) Journal des Praticiens. pag. 301. 
Bientôt à la Société médicale des Hôpitaux, le 7 juin $\left.1907,{ }^{1}\right)$ nous apportions deux observations nouvelles, No. XI et XII et nous complétions notre observation No. VI, Sporotrichose des muqueuses, premier cas de sporotrichoside muqueuse ulcéreuse et d'angine sporotrichosique et nous donnions la démonstration in vivo du saprophytisme du Sporotrichum Beurmanni dans le pharynx. Le cas de de Beurmann, Gastou et Brodier intitulé Sporotrichose gommeuse disséminée avec lésions laryngéesa (25 oct. 1907), dont l'autopsie fut minutieusement faite par Letulle et Debré (férrier 1908), était le premier cas de laryngite sporotrichosique végétante et fut suivi de plusieurs faits semblables.

Notre observation No. XII „Chancre sporotrichosique frontalet sporotrichoselymphangitique centripète" fut le premier exemple de lésion intiale sporotrichosique et de sporotrichose verruqueuse, de lymphangite primitive, d'epidermites acnéiformes et eczématiformes dues au Sporotrichum Beurmanni. Cette importante observation fut encore l'occasion de la découverte du parasite dans les squames et de l'autoculture du pus, fait que confirmaient cinq mois plus tard Duval et Monier-Vinard.

Le 7 juin, nous publiions notre cas No. XI: Gomme sporotrichosique unique, probablement musculaire, due à un Sporotrichum dont nous avons donné la première description sous le nom de Sporotrichum Beurmanni $\delta$, et que Matruchot appellera plus tard Sporotrichum Gougeroti.

Le 26 juillet, nous présentions à la Société médicale des Hôpitaux ${ }^{2}$ ) le $>$ Treizième cas de Sporotrichose $:$ Premier cas de Sporotrichose localisée du bras arec lymphangite gommeuse ascendante*, forme dont les observations

1) Bull. et Mém. de la Soc. méd. des Hôp. de Paris. No. 27, p. 950 et Presse Médic. 1907, No. 61 .

$\left.{ }^{2}\right)$ Bull. et Mém. de la Soc. méd. des Hôp. de Paris. Nr. 27, pag. 950 et Presse Médic. 1907, No. 61. 
de Demoulin et Dural (No. XIV), de Dominici et Duval (No. XVIII) seront de nouveaux exemples.

Notre Mémoire de 1906 contenait l'étude clinique et diagnostique, bactériologique et botanique, anatomique et expérimentale, étiologique et pathogénique des Sporotrichoses.

Des travaux d'ensemble ont bientôt complété chacun des chapîtres de ce premier travail.

Notre deuxième Mémoire, paru en août, septembre, octobre, novembre 1907 dans les Annales de Dermatologie et de Syphiligraphie ${ }^{1}$ ) décrivait les formes tuberculoïdes de ces mycoses et précisait l'anatomie pathologique de leurs lésions. Il complétait l'étude des gommes; il en décrivait les formes nodulaires et diffuses; il en suivait stade par stade l'érolution, il en sériait l'histogénèse; il en faisait la comparaison arec les autres processus inflammatoires chroniques: tuberculeux, syphilitiques et cocciens.

Au point de vue de l'anatomie pathologique générale, l'étude du processus mycosique à marche lente n'allant pas jusqu'à la nécrose, montre tous les stades intermédiaires: vascularites, artérites, phlébites et capillarites folliculaires et giganto-cellulaires. Cette étude histologique éclaire et rénove l'histogénèse générale du follicule et la cellule géante; elle montre qu'il $\mathbf{y}$ a toutes les transitions entre les divers processus nodulaires (pseudo-tuberculoses) et elle explique l'origine de plusieurs erreurs anciennes; elle prouve une fois de plus qu'il n'y a pas de spécificité anatomique, mais seulement une formule - spéciale c, habituelle à tel ou tel processus.

Au point de vue de l'anatomie pathologique spéciale des maladies à champignons, elle individualise une formule commune à tout un groupe de mycoses. Ravaut la retrouve dans un cas de Discomycose, G ou g e r o t et Caraven dans l'Hémisporose, Queyrat et Laroche, dans une parendomycose (ex-blastomycose), de Beurmann, Gougerot et Vaucher, dans une nouvelle 0oïdiomycose (ex-blastomycose). Elle peut être reconnue dans les observations de saccharomycose de

1) De Bearmann et Gougerot. Sporotrichoses tuberculoïdes. Annal. de Dermatol. et de Syph. Août, sept., oct., nov. 1907, pag. 497, 603, 655 (103 pages, 26 fig. et 1 planche en couleur). 
Buschke, et dans certains protocoles de lésions tricophytiques profondes nodulaires décrites par Mä̈ochi, Darier et Hall é l'ont signalée récemment dans un nodule intra-dermique de Favus. Les expériences de contrôle, l'étude des $\gg$ nodules par corps étrangers* poursuivie par Gougerot et Vaucher, ont montré que cette formule à trois zones des mycomes est précisement celle des nodules de résorption des corps étran. gers. ${ }^{1}$ ) Les très-brefs protocoles publiés par les auteurs n'ont fait que confirmer nos descriptions anatomiques.

Notre troisième Mémoire, présenté au Congrès français de Médecine de $1907^{\circ}$ ) et publié dans la Tribune Médicale ${ }^{3}$ ) contenait l'étude d'ensemble de l'Etiologie et de la Pathogénie des Sporotrichoses. Il indiquait le saprophytisme du Sporotrichum dans la nature et la résistance du germe aux agents extérieurs. En 1908 notre découverte du Sporotrichum Beurmanni saurage dans les Alpes françaises donnait la démonstration complète de ce saprophytisme et montrait que ces échantillons sauvages d'abord avirulents, acquièrent par passage sur le rat une virulence au moins égale à celle des Sporotrichum humains. ${ }^{4}$ ) Notre travail indiquait les divers modes d'infection et la multiplicité des agents intermédiaires; il précisait les voies d'inoculation: inoculation cutanée démontrée par la clinique et l'expérimentation un cas d'une inoculation accidentelle chez l'homme rapportée par Sicard et Gougerot l'a confirmé en $1908 ;^{5}$ ) inoculation muqueuse d'origine alimentaire, démontrée par toute une série d'expériences in vivo et in vitro; inoculation cntanée sans solution de continuité de la peau; il indiquait aussi la marche

1) Gourge rot et Vaucher. Pseudo-tuberculoses par corps étrangers. Journal de Médecine interne. 30 avril 1909. No. 12, p. 117.

2) Comptes rendus du Congrès français de Médecine de Paris, 14 et 16 oct. 1907, p. 296.

3) Tribune Médicale, 2 nov. 1907, p. 693.

4) Bull. et Mém. de la Soc. méd. des Hôp. de Paris. 4 déc. 1908. No. 37 , p. 733.

s) Bull. et Mém. de la Soc. méd, des Hôp. de Paris. 10 juill. 1908. No. 25, p. 77. 
de l'infection et ses voies de dissémination. Ce troisième Mémoire a été complété par plusieurs notes parues en 1907. 1908, 1909 nous avons démontré entre autres faits le danger du saprophytisme du Sporotrichum sur les muqueuses et attiré l'attention sur l'importance des porteurs de germes dans l'étiologie, la prophylaxie et la thérapeutique; nous avons prouvé l'existence de la sensibilisation et de l'anaphylaxie sporotrichosiques, ${ }^{1}$ ) ainsi que celle d'une adaptation du milieu au germe, adaptation qui favorise l'éclosion des lésions. Pour expliquer la pullulation du Sporotrichum Beurmanni (germe de virulence habituellement faible), il n'y a donc pas seulement un amoindrissement de la résistance du terrain et une augmentation de la virulence du germe (adaptation du germe au milieu), mais encore et surtout une sensibilisation du terrain par les toxines du champignon vivant en saprophyte: véritable adaptation du milieu au germe. Grâce à toutes nos études, la Sporotrichose est une des maladies dont l'étiologie et la pathogénie sont les mieux connues. Les brèves indications étiologiques contenues dans les observations des auteurs ont pleinement confirmé nos travaux.

Notre quatrième Mémoire sur les Sporotrichoses expérimentales, en collaboration arec Vaucher, a été résumé dans une note présentée au Congrès Français de Mé-

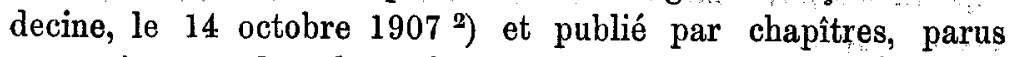
successivement dans les Bulletins et Mémoires de la Société médicale des Hôpitaux de Paris pendant les années 1907 et $1908^{3}$ ) et dans les Comptes-rendus de la Société de Biologie

1) De Beurmann et Gougerot. L'état de sensibilisation des sporotrichosiques. Comptes-rendus du Congrès de Lille 1909 et Bull. et Mém. de la Soc. méd. des Hôp. de Paris. 8 oct. 1909, No. 29, p. 397.

2) Comptes rendus du Congrès franģais de Médec. de Paris. 14 oct. 1907 , p. 301.

9) De Beurmann, Gougerot et Vaucher. Bull. et Mém. de la Soc. méd. des Hôp. de Pa ris, 1907. No. 28, p. 1000 et 1009; Nr. 30, p. 1071 . -1908 . No. 18 et 20 , p. 718,800 et 837 ; No. 24, p. 9 ; No. 25, p. 61 . 
en 1909. ${ }^{1}$ ) Il étudie les Sporotrichoses du cobaye, du lapin, du singe, et surtout celles du rat, de la souris, du chat et du chien.

Non seulement nous avons pu démontrer la virulence du parasite et en reproduire les formes cutanées seules connues en 1906, apportant ainsi des preuves irréfutables de l'autonomie des Sporotrichoses humaines, mais surtout nous avons pu produire toute une série de formes verruqueuses, osseuses, articulaires, synoviales, viscérales, obtenir des ostéo-arthrites, des cirrhoses du foie, des néphrites, des méningites, des endocardites, des pneumonies, des granulies, etc. etc. Ce sont ces expériences qui ont prouvé l'existence des Sporotrichoses profondes, les ont annoncées et les ont fait rechercher. C'est ainsi qu'on a retrouvé chez l'homme les synovites, les arthrites, les orchites, les pyélonéphrites, les ostéites sporotrichosiques, etc. etc... Les inoculations de Lesné et Monier-Vinard sur le lapin et sur la souris, celles de Ravaut et Civatte sur le singe, celles de Lutz et Splendore sur le rat, celles de Brissaud et Rathery sur la souris, etc. ont donné des résultats analoges aux nôtres.

Nos Mémoires sur l'anatomie pathologique, sur l'étiologie et la pathogénie des Sporotrichoses et sur les Sporotrichoses expérimentales, sont restés les seuls travaux d'ensemble sur ces chapitres.

C'est de la fin de 1907 que datent les intéressantes observations de $\mathrm{Ravaut}$ et $\mathrm{Civatte}$, de $\mathrm{Br}$ issaud et $\mathrm{Rathery}$ premier exemple de Sporotrichose fébrile aiguë, le remarquable mémoire de Lutz et Splendore, qui ont découvert et étudié la sporotrichose spontanée du rat, les travaux de Baliña et Marco del Pont, ceux de Greco, enfin les cas de Danlos et Blanc; premiers cas de Sporotrichose palpébrale, etc. etc.

En résumé, au début de mars 1907, on ne connaissait que nos quatre cas de Sporotrichose de de Beurmann; à la fin de 1907, bien qu'un très-petit nombre d'auteurs consentit

1) De Beurmann, Gougerot et Vaucher. Comp. rend. de la Soc. de Biol. T. LXVI, No. 8 et 9, p. 338, 379; No. 14, p. 597. 
à rechercher cette mycose, on ne comptait pas moins de trente observations dont nous faisions le bilan dans un article de l'Ikonographia Dermatologica. ${ }^{1}$ )

1908. - L'année 1908 a été marquée par la découverte du séro-diagnostic mycosique de Widal et Abrami. La sporo-agglutination et la réaction de fixation permettent de faire le diagnostic immédiat de la Sporotrichose, même dans les cas où la culture est impossible et par les co-réactions elles ont ouvert une voie nouvelle pour le diagnostic des discomycoses, des actinomycoses, etc. ${ }^{2}$ ) La valeur de cette méthode a été bientôt confirmée de toutes parts. ${ }^{3}$ ) Brissaud, Gougerot et Gy présentaient à la Société médicale des Hôpitaux de Paris le premier cas de Diagnostic rétrospectif de la Sporotrichose fait par la clinique, contrôlé par la sporo-agglutination et par la réaction de fixation, affirmé par la culture du Sporotrichum Beurmanni resté saprophyte dans le bucco-pharynx. ${ }^{4}$ ) Widal et Joltrain, à la séance suivante, rapportaient un cas semblable. ${ }^{5}$ )

La même année paraissaient aussi les dernièrs chapitres de notre troisième et de notre quatrième Mémoire, en particulier nos études en collaboration arec Vau cher sur les Sporotrichoses du rat, du chien et du lapin; sur l'épreure diagnostique de l'orchite sporotrichosique du rat provoquée par inoculation intra-péritonéale du parasite nous poubliions aussi une note sur l'action de l'iodure de potassium dans la Sporotrichose ${ }^{6}$ ) et notre travail avec Vaucher sur l'Hérédo-Sporotrichose expérimentale. ${ }^{7}$ )

1) Fascic. 3, 1908, p. 79 à 90 .

2) Widal et Abrami. Séro-Diagnostic de la Sporotrichose. Bull. et Mém. de la Soc. méd. des Hôp. de Paris, 19 juin 1908.

3) Widal, Abrami, Brissaud, Joltrain et Weill. Annal. de l'Institut Pasteur. 1y10. No. 1 .

4) Bull. et Mém. de la Soc. méd. des Hôp. de Paris. 1910. No. 1, p. 1.

$\left.{ }^{5}\right)$ Bull. et Mém. de 1a Soc. méd. des Hôp. de Paris. 20 nov. 1908. No. 35, p. 613 ,

6) De Beurmann et Gougerot. Bull. de la Soc. franç. de Derm. et de Syph. 3. Déc. 1908. No. 9, p. 307.

7) Bull. et Mém. de la Soc. méd. des Hôp. de Paris. 18 déc. 1908. No. 39 , p. 876 . 
Enfin un grand nombre de faits confirmatifs intéressants et plusieurs observations de formes nouvelles étaient publiés; Gougerot et Caraven faisaient connaître le premier cas de Sporotrichose spontanée du chien. ${ }^{1}$ ) Le 5 juin, à la même séance de la Société médicale des Hôpitaux de Paris, Sicard, Bith et Gougerot, puis Fage, présentaient les deux premiers cas d'ostéite sporotrichosique démontrée bactériologiquement, localisation que nous devions étudier d'une manière complète dans notre sixième Mémoire. Le 12 juin, Hudelo, Monier-Vinard, Braun et Merle présentent le premier cas de synovitesporotrichosique démontrée par la culture; Widal et Weill, le premier cas d'hémoculture obtenue chez l'homme. Epatobre, Spillmann et Gruyer publiaient un cas de lésions faciales sporotrichosiques avec adénite, sans lymphangite, simulant l'actinomycose; Ga $\mathrm{G}$ cher et $\mathrm{Fouquet}$, un cas de dermite végétante simulant le Kérion trichophytique; Wid al et Joltrain, le premier cas de sporotrichose familiale. C'est encore en 1908 que Castellani à Ceylan a observé les deux premiers cas de Sporotrichose asiatique; que Splendore, à São Paolo du Brésil a signalé un Sporotrichum qu'il croit nouveau et qu'il appelle Sporotrichum asteroỉdes; que Duque à la Havane a publié trois cas de Sporotrichose dans lesquels la méconnaissance de la nature de la maladie a été cause, chez le premier et chez le deuxième malade, d'une double amputation de cuisses et chez le troisième malade d'une amputation de l'avant-bras, exemples frappants des désastres que peut entraîner l'ignorance de la sporotrichose.

En résumé, à la fin de 1908, le nombre des observations de sporotrichose lépassait soixante et $\mathrm{S}$ iredey, dans son compte-rendu des travaux de la Société médicale des Hôpitaux de Paris pendant l'année courante, pouvait conclure: sla Sporotrichose a parcouru en peu de temps une brillante carrière et conquis depuis deux ans une place importante en nosologie."

1) Gougerot et Caraven. Presse Méd. 28 mai 1908. No. 43, p. 337. 
1909. - L'année 1509 vient encore ajouter à l'histoire de la Sporotrichose quelques acquisitions importantes.

$\mathrm{Blanchetière} \mathrm{et} \mathrm{Gouger} \mathrm{ot} \mathrm{dans} \mathrm{les} \mathrm{Comptes-rendus}$ de la Société de Biologie ont publié une série de recherches sur la composition chimique, sur les fermentations et sur les propriétés biologiques du Sporotrichum Beurmanni, du Sporotrichum Schencki et du Sporotrichum Gougeroti et sur leurs teneurs en toxines. Les mêmes auteurs ont étudié les effets sur l'animal des toxines solubles et des toxines insolubles (sporo-éthérine, sporo-chloroformine), des toxines solubilisables (extraits acétiques, alcalins, alcooliques) et des corps microbiens résiduels; ils ont noté l'ébauche d'une dissociation des réactions qui permet une fois de plus de rapprocher la Sporotrichose de la tuberculose. ${ }^{1}$ )

De nombreux faits nouveaux vinrent augmenter le total déjà si élevé des années précédentes. L'observation de Jo s s et Moure démontra par la biopsie et la culture l'existence des adénites sporotrichosiques.

Notre cinquième Mémoire, consacré à la Comparaison des Sporotrichoses et des infections cocciennes: sporotrichoses aiguës, Sporotrichoses à érolution phlegmasique (abcès chaud sporotrichosique), ${ }^{2}$ ) démontra que les manifestations de l'infection sporotrichosique peuvent, par exception, avoir une marche aiguë.

L'observation de Morax et d'Attilio Fava fit connaitre le premier cas de sporotrichose conjonctivale primitive.

Notre étude d'ensemble, faite avec Vaucher, sur la Sporotrichose osseuse et ostéo-articulaire (si$\mathrm{xi}$ ème Mémoire) ${ }^{3}$ ) rassambla tous les faits humains, animaux

1) Blanchetière et Gougerot. Comptes-Rendus de la Soc. de Biol. 30 janv. 1909, No. 5, p. 202 et 17 juillet, No. 26, p. 159. - Blanchetière. Thèse de Paris. 1909. - Gougerot et Blanchetière. Comptes-Rendus de la Soc. de Biol. No. 27 et 28, p. 247 et 350 .

2) De Beurmann et Gougerot. Annal. de Dermat. et de Syph. Févr. 1909. No. 2, p. 81.

3) De Beurmann, Gougerot et Vaucher. Revue de Chirurgie. No. 4. 1909 . p. 661,9 fig. 
et expérimentaux, relatifs à ces localisations fréquentes et graves de la Sporotrichose.

En même temps paraissaient les revues générales de Gougerot sur les Formes cliniques et sur le Diagnostic de la Sporotrichose de de Beurmann ${ }^{1}$ ) qui résumaient l'état actuel de la question et en donnaient la bibliographie complète. ${ }^{2}$ )

L'observation de Sporotrichose ganglionnaire de Achard et Ramond fournit le premier exemple de Sporotrichose du cervicale.

De Beurmann, Gougerot et Laroche, publièrent le premier cas d'acné sporotrichosique ayant servi de porte d'entrée à une Sporotrichose faciale avec lymphangite et adénite. ${ }^{3}$ )

Lerat fit connaître la première observation belge et Bruno $\mathrm{Bloch}$ la première observation suisse. C'est ce dernier qui, dans une étude très-complète, posa le principe des réactions sporotrichosiniques et qui obtient le premier la cuti-réaction sporotrichosinique (6 mai 1909).

$\mathrm{Pierre}$ Marie et Gouge rot montrèrent le premier cas d'ostéite sporotrichosique hypertrophiante primitive du tibia, compliquée de lymphangite gommeuse ulcéreuse ascendante et d'adénite sporotrichosiques ce cas, suivi d'autopsie, permit une étude complète des lésions osseuses et ganglionnaies. ${ }^{4}$ )

Notre étude sur la Sporotrichose cachectisante mortelle, basée sur les deux observations inédites de Maurice Lagoutte et Briau du Creusot réréla des faits d'une gravité exceptionnelle: Sporotrichoses polymorphes avec gommes sous-cutanées et grands

1) Gougerot. Formes cliniques de la Sporotrichose de de Beurmann. Gaz. des Hôp. 17 et 24 avril 1909. No. 44 et 47, p. 537 et 581.

9) Gougerot. Diagnostic de la Sporotrichose de de Beurmann. Lavori e Reviste di Chimia e Microscopia clinica. Vol. I, fasc. 9 .

9) De Beurmann, Gougerot et Laroche. Bull. et Mém. de la Soc. méd. des Hôp. de Paris, 30 avril 1909. No. 15, p. 782.

4) Pierre Marie et Gougerot. Bull. et Mém. de la Soc. méd. des Hôp. de Paris. No. 19, p. 994, 1909. 
abcès disséminés, à localisations ostéo-articulaires, épididymaires et oculaires, conjonctivite, hypopyon, staphylome, perforation de la cornée, issue du corps vitré et perte de l'oeil. ${ }^{1}$ )

Citons encore l'observation de de Beurmann, Gouge rot et Vernes qui fait premier cas d'ostéomyélite gommeuse sporotrichosique abcès intra-osseux du tibia, affirmé par la radiographie. ${ }^{2}$ )

L'observation de de Beurmann, Gougerot et Ver$d u n$, qui contient première mention d'un cas de pityriasis sporotrichosique.

La première observation bernoise de Robert Stein, étudiée le service du Professeur Jadassohn.

L'étude de Pautrier et Lutembacher sur la souscutiréaction sporotrichosinique et nos travaux sur l'intradermo-réaction sporotrichosinique. ${ }^{3}$ )

Le dosage de la toxine par la numération. La démonstration de la non-spécificité de ces réactions en collaboration avec Ravaut et Verdun.

Nos notes sur la sensibilisation et l'anaphylaxie sporotrichosiques, présentés au Congrès de Lille.

L'observation de Danlos et Flandin, premier cas de Sporotrichosedes fosses nasales.

L'observation de de Beurmann et Saint-Girons, premier cas de sporotrichose ulcéreuse localisée où l'on put saisir le mode l'inoculation par une écharde d'épine-rinette.

1) De Beurmann et Gougerot. Bull. et Mém, de la Soc. méd. des Hôp. de Paris. 28 mai 1909. No. 19, p. 1045.

2) De Beurmann, Gougerot et Vernes. Bull. et Mém. de da Soc. méd. des Hôp. de Paris, 4 juin 1909. No. 20, p. 1123.

s) De Beurmann et Gougerot. Bull. et Mém. de la Soc. méd. des Hôp. de Paris, 9 et 16 juillet 1909 . No. 25 et 26, p. 141 et 171. Comptes-Rendus du Congrès de Lille 1909 (et in Thèse de Chopin, Paris 1910). - De Beurmann, Ravant, Gougerot et Verdun. Intra-dermoréactions positives chez des malades porteurs de lésions cutanées non sporotrichosiques. Bull. et Mém. de la Soc. méd. des Hôp. de Paris, 18 nov. 1909. No. 34, p. 541. 
L'année 1909 fut aussi fécondé en observations provinciales et étrangères.

Rapellons la première observation niçoise de Boisseau et Fuleonis.

La première observation marseillaise de Rouslacroix et Wyse-Lauzun.

Les premiers cas toulousains de Rispal et Dalous.

Les nouvelles observations brésiliennes de Lindemberg et de Splendore.

La première observation génevoise de $\mathrm{D} u \mathrm{Bois}$.

Le premier cas africain malgache de Carougeau.

Le premier cas viennois d'O. Krenn et Schrameck.

Le premier cas berlinois de Arndt.

C'est au mois d'août de la meme année que Rochard, Duval et Bodolec, firent connaître le premier cas de pyélonéphrite sporotrichosique.

En novembre l'étude du premier cas de pemphigus sporotrichosique fut faite avec Gougerot dans la clinique du Professeur Landouzy. ${ }^{1}$ )

En décembre l'observation de Josset-Moure identifia le premier cas d'arthrite sporotrichosique.

A la fin de 1909, le nombre des observations dépasse de beaucoup la centaine et il devient impossible de connaître le nombre des faits observés puisque la plupart des cas ordinaires ne sont plus publiés.

La Sporotrichose se montre de plus en plus polymorphe et son domaine de plus en plus s'élargit; on la retrouve dans tous les pays où on la recherche arec soin. Aux Etats-Unis même, la question des Sporotrichoses prend de l'importance. Les deux cas de Schenck et d'Hektoen-Perkins étaient. oubliés au point que Lutz et Splendore, cherchant à identifier leur parasite, n'en avaient même pas eu connaissance; l'heureuse fortune de la Sporotrichose de de Beurmann tire de l'oubli ces faits isolés, et grâce au mouvement que suscitent nos travaux, des cas nouveaux de Sporotrichose sont découverts chez l'homme et en 1909 et en 1910, par les auteurs dont

1) Landouzy. Presse Médic. Nov. 1909. 
nous arons déjà indiqué les noms: Burlew, Trimble et Shaw, Page et Frothingham, J. N. Hyde et Davis, $\mathrm{Duque}$ de $\mathrm{Cuba}$. Le remarquable travail de Page, Frothingham et Paige démontre l'existence aux Etats-Unis de la Sporotrichose spontanée des équidés qui avait déjà été découverte par Carougeau à Madagascar. Ces travaux seront sans doute le point de départ d'une nouvelle étude des Sporotrichoses dans l'Amérique du Nord.

1910. - En 1910, l'attention générale étant attirée sur les Sporotrichoses et beaucoup d'observateurs les recherchant systématiquement, les cas se multiplient de plus en plus. Le diagnostic de la maladie entre dans la pratique courante et les formes communes paraissent si classiques et si banales, que du moins en France, on ne publie plus que les observations présentant un intérêt particulier.

A l'étranger, les observations deviennent plus nombreuses. Notons: les observations de $\mathrm{Campana}$ à Rome; la première observation de Wolf et $\mathrm{H}$ ügel à Strasbourg; la première observation d'Fusebio de Oyarzabal à Madrid; la première observation de Posada Berrio à Medellin (Colombie); les observations italiennes de C. Vignolo Lutati à Turin, de Curcio et de de Carrucio à Rome., etc. etc.

$\mathrm{Au}$ commencement de l'année 1910, paraissait dans le nouveau Traité de Médecine et de Thérapeutique d'A. Gilbert et L. Thoinot notre article Mycoses. Dans un chapitre consacré aux infections mycosiques, nous faisons la première étude d'ensemble sur la pathologie générale des mycoses. Reprenant les travaux anciens de Lucet, de Roger, de Rénon, de Sabouraud, de Bodin, de Brumpt de Plato etc., résumant l'ensemble des recherches que nous poursuivions depuis quatre ans sur les Sporotrichoses les rapprochant des nourelles études de Widal et Abrami, de BrunoBloch, etc., nous faisions un parallèle des infections mycosiques et desinfections bactériennes. ${ }^{1}$ )

$\left.{ }^{1}\right)$ De Beurmann et Gougerot. Mycoses. Traité de Méd. et de Thér. d'A. Gilbert et L. Thoinot. Fasc. IV. 1910. p. 373. Voir encore de Beurmann et Gougerot. Facilités et difficultés du Dia- 
Notre neuvième Mémoire, déposé à l'Académio de Médecine, le 22 février 1910 et couronné par cette Société (Prix Adrien Buisson), est consacré à l'étude clinique et experimentale du Traitement de la Sporotrichose l'action des iodures et de leurs succédanés iodiques, recherche le mode d'action des iodiques et relata nos essais de vaccination et de sérothérapie expérimentales. ${ }^{1}$ )

La même année nous avons confié aux Annales de Parasitologie notre dixième Mémoire qui doit paraître incessamment. Ce travail s'efforce d'élucider la class ification botanique des Sporotrichum pathogènes; il réunit et il compare les avis des plus éniments mycologues français sur la classification des Sporotrichum et sur les discussions botaniques qu'elle soulève. Il s'appuie sur les travaux de Vuillemin, de Guéguen, etc. et en particulier sur le Mémoire que Matruchot a présenté à l'Académie des Sciences le 28 février 1910. Il contient le résultat de nos travaux parasitologiques sur la comparaison des divers Sporotrichum pathogènes de 1906 à 1910 .

Signalons encore les observations de Sporotrichose oculaire de Fava, de Sporotrichose viscérale généralisée de Séguin d'Hana (Tonkin) de Henry de Cayenne, notre cas de Sporotrichose à grands abcès $m u l t i p l e s$, première observation de cette forme, ${ }^{2}$ ) et les cas de fractures spontanées de Bonnet (de Lyon).

En 1910 également, Jeanselme et Paul Chevallier étudiant un cas de Sporotrichose particulièrement intéressant par la multiplicité de ses localisations cutanées, oculaires, testiculaires, cultivaient un Sporotrichum nouveau que Brumpt et Langeron appellent Sporotrichum Jeanselmei;

gnostic des Mycoses. Revue de Médecine et d'Hygiène tropicales. Juillet 1910, T. VII, No. 3 et les Nouvelles Mycoses. Collection Léau té. 1910.

1) Ces derniers essais ont été poursuivis au laboratoire du Professeur Pierre Marie parallèlement à ceux d'A brami, Brissaud et Joltrain au laboratoire du Professeur Widal.

2) De Beurmann, Gougerot, Bith et Heuyer. Bull, et Mém. de la Soc. méd. des Hôp. de Paris, 21 oct. 1910. No. 26, p. 214. 
nous montrons qu'il est très-roisin du Sporotrichum Beurmanni et qu'il semble issu d'une même souche. ${ }^{1}$ )

Les travaux français et étrangers de ces dernières années ont donc fait faire à la question des mycoses et des Sporotrichoses de grands progrès et nous pouvons revendiquer dans cette contribution notre large part.

En effet, ce sont nos recherches de 1906, 1907, 1908, 1909, 1910, qui, en poursuivant l'étude générale des Sporotrichoses et de la plus importante d'entre elles, la Sporotrichose de de Beurmann ont individualisé cette maladie nouvelle et montré sa fréquence qui l'ont séparée de la tuberculose, de la syphilis, de la morve, etc. infections avec lesquelles on l'avait confondue jusqu'à nous.

Nos travaux, confirmés par de nombreux auteurs ont précisé la symptomatologie et décrit les principales formes cliniques des Sporotrichoses: formes hypodermiques, dermiques, osseuses, muqueuses, etc. Ils ont montré que le Sporotrichum Beurmanni peut se localiser dans tous les tissus et créer les lésions les plus polymorphes. Ils ont prouvé que les Sporotrichoses n'intéressent pas seulement le dermatologiste, mais tout médecin, et qu'elles appartiennent à la sgrande pathologie" et à sla pratique de chaque jour.

Nos observations qui ont dégagé les signes cliniques qui permettent de faire le diagnostic au lit du malade avant les épreuves bactériologiques. Nos recherches ont réglé la technique de la culture à froid sur gélose glycosée peptonée et mis à la portée de tout practicien, même dépourvu de microscope et d'étuve et loin de tout laboratoire, le diagnostic scientifique des Sporotrichoses.

Nos travaux ont embrassé presque tous les chapitres de l'étude de ces infections nouvelles; ils ont créé plusienrs d'entre eux: anatomie pathologique, étiologie et pathogénie, reproduction expérimentale, études de la composition chimique du

1) De Beurmann et Gougerot. Comparaison du Sporotrichum Jeanselmei et des Sporotrichum voisins. Bull. et Mém. de la Soc. méd. des Hôp. de Paris, 23 déc. 1910. 
parasite, de ses fermentations et de ses toxines. Toutes ces recherches ont renouvelé la pathologie générale des infections mycosiques.

En même temps que nous individualisions cette nouvelle maladie, nous en règlions le traitement iodo-ioduré général et local, traitement des plus simples, qui guérit en quelques semaines des maladies jadis considérées comme incurables. Autrefois, devant une gomme, devant toute infection chronique nodulaire, on ne laissait au malheureux malade que l'alternative d'être tuberculeux ou syphilitique, à moins que l'on ne le condamnât à quelqu'infection plus sévère encore, à la morve, à la lèpre. Si devant une lésion ostéo-articulaire on rejetait ces diagnostics, c'était pour poser le diagnostic non moins grave d'infection coccienne chronique, qui a été cause d'amputations et de mutilations irréparables. Si l'on songe au pronostic terrible de ces infections, aux lenteurs et aux difficultés de leur traitement trop souvent inefficace, on comprend tous les services qu'a déjà rendus dans la pratique la connaissance des Sporotrichoses.

\section{II.}

Discussions botaniques sur la classification des Sporotrichum.

Le déreloppement de la question des Sporotrichoses s'est poursuivi d'une manière regulière, sans soulever de contestations, sauf en ce qui concerne la classification des parasites. ${ }^{1}$ )

On a discuté sur la signification du genre Sporotrichum, sur l'appellation qu'il convenait de donner aux parasites rétirés des lésions: Trichosporium, Rhinocladium, Sporotrichopsis, etc. On a discuté sur les analogies que présentent les Sporotrichum sauvages et les Sporotrichum pathogènes de l'homme et des animaux. On a surtout discuté sur les rapports qui existent entre les divers sporotrichum pathogènes. Notre

1) Voir nos notes préliminaires Bull, et Mém. de la Soc. méd. des Hôp. de Paris, 23 déc. 1910, et notre Mémoire. (Annales de Parasitol.) 
dixième Mémoire s'efforce d'élucider toutes ces questions botaniques et il aboutit à la classification suivante des Sporotrichum.

Sporotrichum ancestral

\begin{tabular}{|c|c|c|}
\hline \multicolumn{2}{|l|}{$\begin{array}{c}\text { Sporotricham } \\
\text { Schencki-Beurmanni }\end{array}$} & \multirow[t]{2}{*}{$\begin{array}{l}\text { Sporotrichum } \\
\text { Gougeroti }\end{array}$} \\
\hline $\begin{array}{c}\text { Sporotrichum Sporotrichum } \\
\text { Jeanselmei }\end{array}$ & $\begin{array}{l}\text { Sporotrichum } \\
\text { Beurmanni }\end{array}$ & \\
\hline & $\begin{array}{l}\text { Sporotrichum } \\
\text { Beurmanni } \\
\text { var.indicum }\end{array}$ & $\begin{array}{c}\text { Sporotrichum } \\
\text { Beurmanni } \\
\text { var. asteroides }\end{array}$ \\
\hline
\end{tabular}

Sporotrichum (?) Dori.

Le seul point qui demande de nouvelles études est la question des affinités du Sporotrichum Schencki et du Sporotrichum Beurmanni. ${ }^{1}$ Le Sporotrichum Schencki et le Sporotrichum Beurmanni sont-ils différents, quoiqu'issus d'une même souche? Sont-ils identiques, ou tout au moins n'y a-t-il entre eux que de minimes différences de races? La question que nous croyions tranchée a été soulevée de nouveau par les travaux nord-américains de 1909 et de 1910.

Pour comprendre l'état actuẹl de la question, il est indispensable de rappeler comment l'étude comparative de ces deux parasites a été poursuivie.

Smith et $\mathrm{Schenck}, \mathrm{Hektan}$ et Perkins décrivient en 1898 et en 1900 deux échantillons nord-américains de Sporotrichum (échantillon $\mathrm{S}$ chenck et échantillon Hektœn), et, les ayant comparés, ils conclurent à leur identité: leur.parasite est le Sporotrichum Schencki dont Foulerton donna une bonne étude en 1901. Nous appellons leurs deux échantillons $>\mathrm{Schenck}$ initialk, $* \mathrm{Hekt}$ n initial , et, puisque la description du Sporotrichum Schencki a été faite d'après ces deux échantillons, ce sont ces échantillons qui doivent servir de critérium et non pas les échantillons trouvés depuis cette époque.

Matruchot et Ramond, en 1905 , sans connaitre les travaux nord-américains, décrivirent un échantillon cultivé à Paris

1) Voir notre article des Bull. et Mém. de la Soc. méd. des Hôp. de Paris, 23 déc. 1910. 
par de de Beurmann et Ramond en 1903 et l'appellèrent Sporotrichum Beurmanni.

En 1906, reprenant l'étude des Sporotrichoses, nous fûmes amenés à comparer les parasites appelés Sporotrichum Schencki et Sporotrichum Beurmanni. Nous avions alors pour faire cette comparaison: $1^{\circ}$ Les textes des descriptions américains; $2^{\circ}$ les figures des travaux américains; $3^{\circ}$ deux échantillons de Sporotrichum qu'Hektœn nous avait envoyés comme des exemples typiques de Sporotrichum Schencki.

$1^{\circ}$ La comparaison des textes des descriptions américaines du Sporotrichum Schencki et de nos cultures de Sporotrichum Beurmanni ne donnait pas de dissemblances microscopiques, mais indiquait des différences macroscopiques.

Schenck dit: "La surface de la colonie est marquée de lignes rayonnantes procédant du centre à la périphérie (Pl. I, fig. a)«. Hektœn dit de même: nombreuses rides transversales. ... il ressemble aux chaînes de montagnes d'une carte de géographie.* Au lieu de ces sillons radiés, à crètes aiguës, analogues aux vallées convergeant vers le sommet d'une montagne, on sait que le Sporotrichum Beurmanni a des circonvolvations très-irrégulièrement enchevêtrées, à crêtes arrondies, analogues aux circonvolutions cérébrales ou intestinales.

Schenck dit: sThe surface is ... stained a hard brown colour, the shade at the periphery being deeper that in the centre. The medium also becomes stained.e (Fig. I. a) Cette figure I. $a$ de Schenck montre que les colonies ne sont pas brunes, mais blanches; leur périphérie seule est parfois brunâtre or, le Sporotrichum Beurmanni typique est brun chocolat, brun noir, ou noir et quand il ne l'est pas entièrement c'est sa périphérie qui est blanche. Il faut remarqưer cependant qu'H e k $\mathrm{t}$ œ dit qu'en vieillissant la culture devient brun foncé. Foulerton écrit: »Dans de certaines conditions, de vieilles cultures peuvent, sur milieux solides, devenir d'une couleur brun sombre ou noir, et, quand cela est arrivé, on verra sous le microscope de nombreux corpuscules parfaitement sphériques, d'une couleur brun clair, représentant probablement des spores 
dégénérées. Or, dès les premiers jours, le Sporotrichum B e urmanni devient toujours brun sur les milieux favorables et non dans certaines conditions seulement et il ne lui faut pas un long vieillissement pour prendre sa coloration typique brun chocolat.

Schenck specifie que la culture du Sporotrichum Schencki sur gélose simple ne diffère de la culture sur gélose glycosée que par l'abondance de la récolte; or, l'aspect du Sporotrichum Beurmanni est totalement différent sur gélose simple et sur gélose glycosée. Foulerton dit encore: -Le Sporotrichum Schencki, sur gélose simple, cultivant à $22^{\circ}$ centigrade, devient en trois à quatre semaines brun-chocolat ou noir. L'addition de $2 \%$ de maltose à l'agar nutritif n'influence pas à un degré appréciable la rapidité ou l'apparence de la croissance. On sait au contraire que sur gélose simple le Sporotricham Beurmanni pousse maigrement, reste constamment blanc et ne devient jamais brun, ni à plus forte raison, noir; c'est seulement sur gélose maltosée ou glycosée qu'il pousse très abondamment et il ne brunit que sur des milieux riches en hydrates de carbone.

Hektœn dit: sur pomme de terre: culture blanche, légèrement brunâtre, grise ou jaunâtre*. Les colonies les plus vieilles se décolorent: , The older growths become discoloured at the same time as the potato is darkened.e Foulerton dit encore: "Plus tard, la couleur change et devient brun clair. " ${ }^{1}$ ) Au contraire, la culture de Sporotrichum Beurmanni est noir d'encre sur pomme de terre glycérinée (sauf pléomorphisme).

$2^{\circ}$ On pouvait se demander si les différences que nous venons de signaler n'étaient pas dues à une interprétation discutable des textes. Or l'étude des figures américaines montre des différences encore plus marquées. Ces planches représentent en effet des cultures blanches à stries rayonnantes, peu ou pas circonvolvées, dont l'auréole seule est pigmentée; leur aspect est donc différent de celui de nos échantillons de Sporotrichum Beurmanni.

1) Cette absence de pigmentation n'est pas due à la pauvreté en spores, car Foulerton ajoute: "Microscopiquement... nombre relativement énorme de spores et peu de mycélium." 
$3^{\circ}$ La comparaison directe de nos échantillons français de Sporotrichum Beurmanni et des deux échantillons de Sporotrichum Schencki, qu'Hektœn nous avait envoyés, ${ }^{1}$ ) confirmait l'impression donnée par la lecture attentive des textes et par l'examen des planches.

Pourtant, connaissant déjà les pléomorphismes de ces parasites, sachant que les échantillons Schencki n'araient pas été entretenus sur milieu $S a b o u r a u d$, nous nous demandions s'il s'agissait de différences fixes d'espèces ou de simples différences pléomorphiques d'un même Sporotrichum, pléomorphisme dû aux conditions défavorables du milieu de culture. Aussi, dans notre Mémoire de 1906, n'ayant pu suivre ces parasites que pendant quelques mois, nous n'osions conclure et nous écrivions: "Il nous est encore impossible de dire s'il s'agit d'espèces roisines ou identiques. “ ${ }^{2}$ )

Les annés suivantes de 1907 à 1910 , nous avons poursuivi l'étude comparative de tous les Sporotrichum pathogènes que nous avons pu nous procurer. Les différences entre tous les échantillons de Sporotrichum Beurmanni nous ont semblé toujours réductibles, si bien que nous affirmions l'unité de cette espèce avec la possibilité de pléomorphismes secondaires variés. $\mathrm{Au}$ contraire, les différences entre nos $\mathrm{Sporotri-}$ chum Beurmanni et l'échantillon Hektœn-Gougerot de Sporotrichum Schencki restèrent évidentes et fixes. Nous notions des différences microscopiques dans la

1) Pour la commodité du langage, appelons avec certains auteurs culture Hektœen-Gongerot cet échantillon qu'Hektcen nous envoya en 1906. Nous le distinguons ainsi des cultures initiales d'Hektœn, que nous appelons ,Hektœn-initials.

$\left.{ }^{2}\right)$ Hektœn, dans sa lettre d'envoi, nous disait que ses cultures ssemblent maintenant avoir perdu le pouvoir de produire des spores, ce qui les différencie des générations précédentese. Mais cette absence de spores n'est pas constante: sur certains tubes de cet échantillon HektœnGougerot de Sporotrichum Schencki nous avons vu des spores. De même Matruchot, de même Pinoy ont vu le champignon sporulé; ils en ont même donné des dessins.

Remarquons, pour éliminer l'objection d'un pléomorphisme grossier, que les cultures sporulées de l'échautillon Hektœn-Gougerot ne différaient pas macroscopiquement des cultures asporulées. 
richesse des spores, la direction et l'agmination des filaments, différences que confirma $\mathrm{Matru}$ ch ot le plus $\mathrm{Bl}$ anch e tièr e et Goug erot signalaient des différences de pouvoir fermentatif. Nous résumions nos études en un tableau paru dans l'article Mycoses du Nouveau Traité de Médecine et de Thérapeutique d'A. Gilbert et de L. Thoinot.

\section{Sporotrichum Beurmanni Sporotrichum Schencki}

\section{Optimum thermique.}

Cultures difficiles, mais possibles à 38 degrés. Optimum 22 à 30 degrés: donc développement plus lent.
Cultures faciles à 38 degrés. Optimum 30 à 38 degrés: donc développement plus rapide.

Aspect macroscopique des cultures sur gélose glycosée peptonée de Sabouraud (milieu d'épreuve).

Pigmentation rapide et complète. Colonies toujours très colorées, de teinte chocolat ou noire.

Circonvolvations à la façon des circonvolutions cérébrales.
Pigmentation très lente, le plus souvent inconstante ou absente. Colonies peu colorées ou blanches en général.

Sillons presque rectilignes, divergeants à partir d'un centre comme des vallées du cône d'un volcan.

Aspect microscopique des cultures sur lames sèches et en gouttes pendantes.

Filaments mycéliens de $2 \mu$ de large plus rectilignes, quelquefois agrégés, mais surtont enchevêtrés, non parallèles. Spores de 3 sur 5 à $6 \mu$, très-nombreuses, insérées sur de longs filaments on à l'extrémité de filaments latéraux courts ou longs.

Chlamydospores.
Filaments mycéliens de $2 \mu$ de large plutôt curvilignes, onduleux, presque toujours agrégés et parallèles en faisceaux, sans enchevêtrement habituel. Spores très-rares, souvent même absentes, insérées le long et surtout à l'extrémité de longs filaments. Peu ou pas de conidiophores courts latéraux.

Pas de chlamydospores connues.

\section{Caractères biologiques.}

Fait fermenter le saccharose.

$\mathrm{Ne}$ semble pas faire fermenter le lactose, etc.
Fait fermenter le lactose.

$\mathrm{Ne}$ semble pas faire fermenter le saccharose, etc. 
Nous concluions: "Ces différences sont absolument fixes sur milieu d'épreuve. Nous ne savons pas si, originairement, les deux Sporotrichum, le Sporotrichum Schencki et le Sporotrichum Beurmanni étaient identiques, mais nous affirmons qu'actuellement ils sont nettement distincts et qu'on ne peut faire le passage de l'un à l'autre. Depuis 1906 que nous suivons les deux échantillons de Sporotrichum Schencki, que nous a envoyés Hektœn et que nous collectionnons les Sporotrichum Beurmanni français et étrangers, jamais le Sporotrichum Schencki n'a pu être transformé en Sporotrichum Beurmanni.

- Depuis des années que nous manipulons ces parasites, aucun des nombreux échantillons de Sporotrichum Beurmanni ne s'est transformé et fixé sous forme de Sporotrichum Schencki: sourent on obtient sur de maurais milieux des cultures blanches de Sporotrichum Beurmanui ressemblant macroscopiquement au Sporotrichum Schencki; mais la ressemblance se borne là, toutes les différences persistent et le report sur pomme de terre ou sur betterave glycérinée redonne avec le Sporotrichum Beurmanni une culture noire, alors que la culture du Sporotrichum Schencki (échantillon Hektœn-Gougerot) est constamment blanche sur ce milieu. Or, il est évident qu'il faut juger un parasite d'après ses cultures habituelles fixes et non d'après un pléomorphisme exceptionnel et passager, facile à ramener au type habituel.

Matruchot, Pinoy, Vuillemin confirmaient bientôt nos recherches avec le même matériel: Sporotrichum Beurmanni français et échantillon Hektœn-Gougerot de Sporotrichum Schencki que nous leur avions transmis. Matruchot donnait des deux parasites les descriptions comparatives suivantes:

Sporotrichum Schencki (échantillon HektœnGougerot).

La culture est restée indéfiniment incolore; toutefois, à la suite de repiquages, un pigment brunâtre
Sporotrichum Beurmanni (de toutes provenances).

Les cultures deviennent constamment brunes, brun chocolat, brun noir sur milieu d'épreuve. 
est apparu sur des portions aériennes de mycélium agrégé.

Le mycélium stérile porte de très nombreuses ramifications contournées et irrégulières.

Dans les régions fertiles aériennes, c'est-à-dire dans les parties de la culture où la fructification se fait normalement, les conidies naissent de Ja façon suivante: Sur une branche du mycélium apparaît d'abord à l'extrémité un petit renflement qui devient une spore. Lorsque cette spore est formée, une deuxième apparaît à côté ou un peu au-dessous, puis une troisième, et il se fait ainsi un petit bonquet de spores nées isolément et successivement. En même temps, ou peu après, apparaissent sur les cellules sous-jacentes de nouveaux bourgeonnements qui donnent naissance à des spores isolées, disposées en bouquet ou non.

Ces spores sont incolores, et, sauf exception, non pédicellées, comme celles qu'ont figurées Schenck, Hektœn et Perkins; elles rentrent tout à fait dans le type de fructification $S$ porotrichum. Mais dans les parties très humides de la culture, le processus de formation des spores subit une modification singulière qui conduit à un type aberrant de fructification. Là, les spores sont fréquemment disposées en chapelets à développement centripète et nous avons même pu observer en place des files régulières de 5,6 et 8 spores.

Comment deux dispositions aussi différentes des mêmes spores peuvent-elles se rencontrer sur la même culture et pour ainsi dire sur le même individu? Nous avons pu nous en rendre compte et concilier
Le mycélium est incolore, rampant, fin, d'un calibre assez constant ( $2 \mu$ de diamètre), très abondamment ramifié et enchevêtré.

La fructification se fait normalement sur les parties aériennes du mycélium; les filaments sporifères sont couchés, non dressés.

Les fructifications sont très riches en spores; toute une longue portion terminale des filaments est couverte de spores. L'ensemble constitue de grosses masses cylindriques d'une largeur de $19 \mu$ environ, sorte de boudins parfois contournés et ramifiés et semblant au premier abord formés uniquement de spores agglomérées.

Les spores toujours pigmentées sont isolées les unes des autres, éest-à-dire ne sont pas disposées en chapelet. Elles naissent solitaires sur le mycélium, en nombre variable, mais généralement très grand, sur chaque article du thalle; elles sont disposées sans ordre apparent. Exceptionnellement, sur de courts et minces rameaux latéraux, qui semblent être des stérigmates plus développés, peuvent naître côte à côte et successivement deux à cinq spores, et plus, disposées, dès lors, à maturité, en petit bouquet. Mais cette exception apparente rentre encore dans la règle qui est que les spores sont solitaires et naissent isolément.

La spore encore insérée sur le filament est généralement piriforme. Tantôt elle se prolonge insensiblement par un pédicule qui aboutit à un stérigmate très fin, long de 1 à $2 \mu$, large de $0.5 \mu$; elle est alors nettement pédicellée. Tantôt, tout en gardant la forme en poire, elle s'insère directement sur le my- 
ces deux formations en apparence contraires l'une à l'autre, en suivant le développement des formes intermédiaires. L'un des cas observés est particulièrement instructif à cet égard. On $y$ voit quatre spores disposées en un chapelet irrégulier. La spore basale 4, née la dernière, est un renflement du filament qui s'est produit, non pas au-dessous de la spore précédente, mais latérament. Même disposition de la spore 3 par rapport à la spore 2 et de celle-ci, par rapport à la spore terminale, née la première. Or, que la spore dernière, née se soit formée un peu a u-dessus de la spore précédente au lieu de se produire latéralement, et nous aurions eu la fructification normale du Sporotrichum. Au contraire, que la spore dernière-née se soit formée a u-dessus de la précédente et nous aurions eu une fructification en chapelet, à développement centripète tout à fait normal, si la formation se continuait régulièrement.

Pas de chlamydospores connues. célium sans interposition de stérigmate; elle est alors parfaitement sessile. Tantôt, enfin, elle s'insère sur le flament par une base assez large; il n'y a plus trace de pédicelle ou de stérigmate.

Le Sporotrichum Beurmanni peut donner naissance à des chlamydospores, c'est-à-dire à des spores enkystées, munies d'une membrane épaisse. De Beurmann et Gougerot en avaient déjà signalé d'intercalaires sur le trajet des filaments mycélium et de terminales à l'extrémité de rameaux latéraux renflés; nous avons pu, nous aussi, en observer de latérales et de terminales, peut être plus caractéristiques que les intercalaires par leur forme subsphérique et par les goutelettes huileuses qu'elles renferment. Elles apparaissent dans les vieilles cultures, dans les points où se produisent de petites touffes floconneuses de mycélium blanc; elles sont abondantes, surtout sur les portions agrégées du mycélium; ce sont évidemment des organes de conservation.

Vuillemin trouvait même des différences si grandes entre les deux parasites qu'il les classait dans des genres différents: Sporotrichum Schencki d'une part et Rhinocladium Beurmanni d'autre part.

Calvin Gates Page, Langdon-Frotingham et J. B. Paige, comparant le Sporotrichum Schenki et le Sporotrichum Beurmanni, disent en 1910 (p. 146): *Les descriptions publiées en 1898 et 1900 par Schenck et par Hektœn ont été lues par de Beurmann et Gougerot après la publication de leur premier cas de 1903, et citées dans l'étude complète de leur parasite publié en 1906. Ils insistent sur certaines différences microscopiques entre les cultures américaines et les cultures françaises $s u f f$ isantes pour en 
faire des espèces distinctes, mais si légères, nous semble-t-il, qu'elles sont de petite importance pratique.*

La question nous semblait donc tranchée en faveur de la distinction des deux parasites Sporotrichum Schencki et Sporotrichum Beurmanni. Nous les jugions distincts quoique très-proches et sans doute issus d'une même souche ancestrale: "La seule cause d'erreur, disions-nous, serait que l'échantillon Hektæn-Gougerot de Sporotrichum $\mathrm{Schencki}$ représentât un pléomorphisme du Schenck initial ou de l'Hektæn inital.“

Mais nous avons déjà insisté sur les deux points suivants.

$1^{\circ}$ Depuis que l'on entretenait le premier échantillon $\mathrm{Ma}$ truchot-Ramond de Sporotrichum Beurmanni sur de mauvais milieux, on n'avait vu que des pléomorphismes variables et toujours réductibles au type Sporotrichum Beurmanni. Or, les particularités qu'offrait l'échantillon $\mathrm{Hektœn}$ Gougerot du Sporotrichum Schencki étaient remarquablement fixes et absolument irréductibles.

$2^{\circ}$ Nous étions obligés d'admettre que l'échantillon de Sporotrichum Schencki qu'Hektoen nous avait envoyé était vraiment caractéristique? Puisqu'Hektœn nous l'avait donné comme typique du Sporotrichum Schencki, il nous était impossible de ne pas juger de ce parasite par cet échantillon, d'autant mieux que l'étude de cetéchantillon concordait avec les descriptions et surtout avecles figures nord-américaines. ${ }^{1}$ ) Puisque cet échantillon présentait avec le Sporotrichum Beurmanni des différences fixes et irréductibles, nous devions conclure à la distinction des deux parasites de Schenck et de de Beurmann.

Tel était jusqu'à ces derniers mois l'état de la question. Les travaux nord-américains de Burlew, de Trimble et

1) La seule divergeance entre la description de Schenck (p. 286 et 287 ) et d'Hekton, observée sur les cultures de Sporotrichum $\mathrm{Schencki}$, est que Schenck parle de la teinte brunâtre des colonies; or, nous l'avons déjà dit ci-dessus, les figures de Schenck nous représentent des colonies blanches avec parfois un liséré brunâtre périphérique, et c'est ce que nous avons toujours vu sur les cultures de l'échantillon Sporotrichum Schencki Hektœn-Gougerot. 
Shaw, de Page et Frothingham, de J. N. Hyde et Davis, viennent de la replacer sur des données nouvelles. Ces auteurs appellent leurs parasites trouvés en 1901-1910 Sporotrichum Schencki. Davis est venu nous apporter ses cultures et ses documents. Élève d'Hektœ $\mathrm{n}$, travaillant dans le laboratoire du savant bactériologiste américain, D a v is était à même de comparer son échantillon avec le Sporotrichum Schencki d'Hektœn. Hyde et Davis, ayant eu entre les mains les cultures équines de Mohler, de Page et Froth ing a $\mathrm{m}$, les cultures humaines de $\mathrm{Zurawski}$, ont pu d'abord montrer que ces cultures étaient identiques aux leurs. D'après les documents et les planches de Burlew, de Trimble et de $\mathrm{Shaw}, \mathrm{Hyde}$ et $\mathrm{Davis}$ ont la conviction que ces parasites sont également identiques; mais Davis n'a pu en faire la comparaison directe, car il n'a pas vu leurs cultures.

Davis, après avoir comparé ses cultures arec les cultures de l'échantillon de Sporotrichum SchenckiHektœn initial, conservées au laboratoire d'Hektœn, est persuadé, nous a-t-il dit, que les parasites sont les mêmes. Pourtant, différentes particularités que nous lui avons montrées ne l'avaient pas frappé et il faudrait interroger Hektœn sur ces points. Or, les cultures de l'échantillon de Davis qu'il appelle „Sporotrichum Schencki" sont, sinon identiques à nos échantillons que nous appelons Sporotrichum Beurmanni, du moins intermédiaires entre le Sporotrichum Schencki, échantillon Hektæn-Gougerot et le Sporotrichum Beurmanni. Cette ressemblance s'impose à première vue; elle a été confirmée par l'étude complémentaire que nous venons de faire par les examens de Matruchot. ${ }^{1}$ )

On peut donc adopter actuellement un des trois interprétations suivantes :

I. Ou bien l'échantillon Hektœn-Gougerot de Sporotrichum Schencki est bien un Sporotrichum Schencki et représente le $*$ type de ce parasite, et alors le Sporotrichum Schencki et le Sporotrichum Beurmanni sont des espèces voisines, mais différentes, car il suffit

1) Communication écrite. 
d'aroir vu une fois un échantillon Hektœn-Gougerot de Sporotrichum Schencki et un echantillon de Sporotrichum Beurmanni pour les différencier. Dans ce cas, les nouveaux échantillons nord-américains de $\mathrm{Davis}$ et autres ne seraient pas des Sporotrichum Schencki mais des Sporotrichum Beurmanni. On n'aurait cultivé que deux fois le Sporotrichum Schencki (Schenck, 1898; Hekton et Perkins, 1900).

II. Ou bien, le Sporotrichum Schencki et le Sporotrichum Beurmanni, dérivant de la même souche, sont aujourd'hui différents mais ils sont reliés par de nombreux intermédiaires, tels que l'échantillon de $\mathrm{Hyde}$ et $\mathrm{Davis}$.

III. Ou bien, l'échantillon Hektœn-Gougerot de Sporotrichum Schencki est un pléomorphisme fixe et irréductible du Sporotrichum Schencki, différent des échantillons $\mathrm{Schenck}$ initial et $\mathrm{Hektœn}$ initial. D'après cet échantillon Hektœn-Gougerot de Sporotrichum Schencki, envoyé on ne sait pourquoi comme typique, on ne saurait donc juger le véritable $S$ porotrichum Schencki. Le véritable $\mathrm{Sporotrichum} \mathrm{Schencki} \mathrm{serait} \mathrm{tout} \mathrm{autre;}$ il serait représenté, par exemple, par l'échantillon de HydeDavis; mais alors, puisque nos Sporotrichum Beurmanni et cet échantillon de Hyde-Davis sont identiques, le Sporotrichum Schencki et le Sporotrichum Beurmanni seraient identiques; ils ne formeraient qu'une même espèce, le Sporotrichum Schencki-Beurmanni, pour employer l'expression de Gréco (1908).

$\mathrm{Si}$ cette identification venait à être confirmée, il n'en resterait pas moins que le parasite unifié, dénommé Sporotrichum Schencki-Beurmanni, peut revêtir deux aspects.

Le premier aspect, rare, caractérisé par la blan. cheur des colonies et leur peu de tendance à la pigmentation, leur sillonnage radié, leur tendance à l'agmination de filaments parallèles, est l'aspect décrit par les textes américains et figuré par les planches de $\mathrm{Schenck}$ et $\mathrm{d}^{\prime} \mathrm{Hektœn}$ en 1898 et 1900 , aspect qui a servi à la description du Sporotrichum $\mathrm{Schencki}$ et que nous avons retrouré au maximum sur les 
échantillons Hekton-Gougerot de Sporotrichum Schencki. Cet échantillon de Sporotrichum Schencki représenterait donc l'exagération des caractères de cet aspect. Il faudrait appeler cette apparence spéciale aspect ou variété Schencki du Sporotrichum Schencki-Beurmanni.

L'a utre aspect, plus fréquent, constant lorsque la culture initiale est faite sur gélose $S$ abouraud, est caractérisé par des colonies brun-chocolat ou noires, par une pigmentation constante plus ou moins rapide, par des circonvolvations irrégulièrement contournées et entrecroisées, fines, à la manière de circonvolutions cérébrales, ne présentant que rarement l'aspect montagneux et les sillons radiés presque rectilignes du centre à la périphérie, enfin par des spores nombreuses et des filaments enchevêtrés. C'est l'aspect que nous avons tant de fois décrit et figuré, ${ }^{1}$ ) l'aspect qui a servi à la description du Sporotrichum Beurmanni et qui est maintenant devenu classique. Il faudrait donc appeler cet aspect »aspect « ou variété Beurmanni du Sporotrichum Schencki-Beurmanni. ${ }^{2}$ )

On voit que la question ne peut être résolue que par l'étude de tous les échantillons nord-américains: Sporotrichum Schenck initial, Hektœn initial, etc. Daris doit nous envoyer la collection complète et doit aussi refaire avec Hektœn cette étude parallèlement à la nôtre.

Pour conserver la première et la deuxième conception, il faudra démontrer que les échantillons Schenck initial, Hektoen initial, répondent bien à la description américaine de 1898-1900 et aux planches annexées; que l'échantillon Hektœn-Gougerot de Schencki est un Sporotrichum $\mathrm{Sch}$ e cki, sinon complètement typique, au moins suffisamment caractéristique. Il faudra alors réserver aux deux seuls échantillons de Schenck et d'Hektœn l'appellation Schencki

1) Par exemple voir Annales de Dermatol. et de Syph. 1906. Bull. et Mém. de la Soc. méd. des Hôp. de Paris, 7 juin 1907. Teonographia dermatologica, 1908; Riviste e Lavori di microscopia clinica, 1909, etc.

2) Les derniers échantillons nord-américains de $D$ avis seraient ainsi des variétés Beurmanni du Sporotrichum Schencki-Beurmanni. 
et ne pas la donner aux nouveaux échantillons nord-américains (de Hyde-Davis) qui ont l'aspect Beurmanni.

Pour adopter la troisième conception, il faudra montrer que les tubes initiaux ou les premiers repiquages $\mathrm{Schencki}$ de Schenck et d'Hektœn sur milieu différenciateur, sont identiques de tous points aux tubes de Beurmanni, que l'échantillon Hektæn-Gougerot de Sporotrichum Schencki est un pléomorphisme et ne peut definir le Sporotrichum Schencki et par conséquent que la description et les planches américaines de 1898-1900 étaient incomplètes et ne répondaient qu'à un aspect du parasite. Cet aspect, ayant été seul décrit alors, doit conserver le nom de $\mathrm{Sch} \in \mathrm{ncki}$. L'autre aspect $d u$ parasite, ayant été décrit pour la première fois par Matruchot et Ramond, par de Beurmann et Ramond et par nous, doit garder le nom de Beurmanni.

C'est la comparaison des cultures sur un milieu différenciateur, tel que la classique gélose de $\mathrm{S}$ abouraud et non une comparaison des textes ou des cultures pléomorphisées, qui seule peut nous laisser l'espoir de trancher nos doutes actuels.

La question pourra être résolue si les tubes initiaux de Schenck et d'Hektœn ont été conservés; il suffira de comparer ces tubes initiaux de 1898 et de 1900 arec nos tubes de Sporotrichum Beurmanni. Mais si les tubes des cultures initiales de Schenck et d'Hektœn et leurs premiers repiquages sur gélose glyeosée ou maltosée (seuls milieux de différenciation possibles) sont perdus, ou si leur aspect n'a pas été fixé par d'autres planches que celles de 1898 et de 1900 , il sera impossible de faire les comparaisons nécessaires et l'on ne pourra aroir sur ce sujet que des souvenirs et des impressions, mais non une certitude.

III.

Intérêt pratique et doctrinal des Sporotrichoses.

L'exposé historique que l'on a lu montre le double intérêt pratique et doctrinal de l'étude des Sporotrichoses. 
L'intérêt pratique, pronostique, thérapeutique et économique des Sporotrichoses en général et de la Sporotrichose de d e B e urmann en particulier, est considérable; la connaissance de ces infections, en prouvant la fréquence des mycoses, nous force en effet à les rechercher systématiquement dans un grand nombre de cas où on ne les aurait pas soupçonnées autrefois; elle nous permet de poser facilement un diagnostic certain, de guérir rapidement le malade, de le délivrer de la menace d'accidents ou de sequelles lointaines, elle rend l'ouvrier à son travail et restaure le moral du malade en lui rendant la confiance qu'il avait perdue. C'est parce que ce diagnostic de Sporotrichose permet le guérir des sujets condamnés sans lui à une longue maladie que chaque praticien doit toujours l'avoir présent à l'ésprit; c'est parce qu'il n'en est pas de plus simple que le médecin serait inexcusable de ne pas savoir le vérifier.

Nous ne pouvons mieux faire que de reproduire ici ce que disait le Professeur L. Landouzy dans une de ses belles Cliniques de l'Hôpital Laënnec. "Depuis trente ans, je répète et démontre, * disait-il, que tant vaut le médecin savant, tant vaut le médecin praticien. Tout homme qui veut être à la hauteur de sa tâche de praticien, et je n'en sais pas de plus honorable, ne peut ni concevoir, ni réaliser sa tâche s'il n'a pas l'ambition d'être savant-médecin, c'est-à-dire de ne rester étranger à l'étude d'aucune des maladies ou des affections dont l'ignorance pourrait porter préjudice au client venu à l'improviste pour réclamer ses soins. Maintes et maintes fois j'ai insisté dans ces Leçons sur les conséquences funestes de la méconnaissance des formes frustes ou larvées de la syphilis, de la paralysie générale commençante, du tabès, des bacillo-tuberculoses, du myxœè̀me, que nul n'a le droit d'ignorer, quand il prétend pratiquer la médecine. Pour appuyer mon dire, je ne puis prendre de meilleur exemple que ce cas de Sporotrichose qui s'est présenté à notre consultation, la bonne femme qui en était atteinte se décidant à consulter après des semaines de douleurs et de plaies * que rien ne soulageait ....

Cette maladie était, avant les travaux de de Beurmann et Gougerot, confondue, soit avec la tuberculose, soit 
arec la syphilis: le malade supportait toutes les funestes conséquences d'un diagnostic erroné, d'un pronostic faussé, d'un traitement inopportunément ordonnancé ....

Pris pour un tuberculeux, on condamnait le sporotrichosique au repos prolongé et trop souvent à la suralimentation; on essayait, mais sans grande conviction, des topiques locaux, et voyant les plus énergiques échouer, on s'en remettait à la natura medicatrix pour guérir le malade; la maladie s'aggravait lentement . . . S si, par hasard, le patient guérissait à la suite de médications dont les iodo-tanniques avaient fait les frais, on gardait toute espèce de réserves pour son avenir; on arait toutes difficultés à ne pas le voir promis à d'autres manifestations bacillaires?

Pris pour un syphilitique, traité par le mercure, le sporotrichosique voyait sa maladie se prolonger et s'aggraver; heureux si, revenant à la vieille pratique d'associer l'iodure au mercure, le médecin voyait les gommes guérir; mais le patient restait justiciable de toutes réserves pronostiques, puisque la syphilis, qui semblait l'avoir atteint dans le passé, le menaçait dans l'avenir.

Or, savoir dépister et reconnaître, sous l'un quelconque de ses aspects, la Sporotrichose, c'est la guérir, puisque l'on possède un traitement quasi-spécifique, le traitement iodo-ioduré; c'est rassurer le malade sur son avenir, puisque, sauf exceptions, la Sporotrichose est une infection bénigne. On voit tout de suite quels services nous ont rendus M. M. de Beurmann et Gougerot en individualisant cette mycose; en nous apprenant à la reconnaître cliniquement, grâce à une série de signes qu'ils ont minutieusement groupés; en nous donnant la méthode du diagnostic simple et rapide de la culture à froid qui porte si justement leurs noms. G ou g e r ot perfectionnait encore par l'artifice de la coulée de pus sur le verre sec cette technique qui permet un diagnostic précoce dès le troisième jour, souvent dès le second jour. Widal et $\mathrm{Abrami}$, en découvrant le séro-diagnostic sporotrichosique, dotaient la clinique d'une méthode de diagnostic immédiat. Le diagnostic clinique et bactériologique de la sporotrichose se trouvait mis ainsi à la portée de tout le monde. 
Faire, dans le cas particulier, vite et bien un diagnostic d'où découleront un pronostic exact et une thérapeutique efficace, ce n'est pas seulement une satisfaction pour tout praticien épris d'art médical, c'est encore nous donner la sensation de servir au mieux les intérêts qui nous sont confiés.

Méconnaître une Sporotrichose, c'est, pendant des trimestres et des semestres, laisser dans la souffrance et l'inactivité, c'est garder à l'hôpital un ouvrier, père et soutien de famille, c'est le mettre, lui et sa famille, à la charge de la collectivité, alors qu'un diagnostic exact le guérirait en un à deux mois et le rendrait à la vie commune. Mal diagnostiquer, mal pronostiquer et inopportunément traiter nos malades, songez-y, e'est encore nous exposer à ce que: par notre insuffisance, un dom. mage ayant été commis vis-à-vis de l'individu, de la famille, la société s'en prenne au médecin du dommage, matériel toujours, moral sourent, dont le praticien aura été l'occasion ....

Combien sont instructives les observations relatées par M.M. Ravaut et Civatte et par M. Moure.

La malade de Ravaut et Civatte, prise pour une tuberculeuse, était confinée au lit depuis sept mois, arrêtée dans son travail; son affection s'aggravait; le diagnostic est réformé et en un mois elle guérit.

Le malade de Moure, qui traînait depuis trois ans d'hôpital en hôpital, avait subi quatre opérations, et son ostéite sporotrichosique continuait d'évoluer; de guerre lasse, on lui proposait l'amputation! Dès que le diagnostic de Sporotrichose fut posé, le malade, mis à l'iodure, guérissait en six semaines sans opération! Pareils faits sont nombreux ${ }^{\mathbf{1}}$ ) et l'on pourrait citer bien d'autres exemples d'observations dans lesquelles il a

1) La simple suspicion de Sporotrichose a suffi parfois à guérir les malades: Du Cazal, médecin en chef de l'Hôpital de Monaco, nous a envoyé la relation de deux cas particulièrement démonstratifs. SLe premier malade, nous écrit.il, était dans le service lorsque je le pris à mon arrivée ici, en octobre 1907. Mon prédécesseur me dit que c'était un moribond, couvert d'ulcères tuberculeux et an lit duquel on ne s'arrêtait même plus. Etonné le lendemain de ne rien trouver dans ses poumons, je pensai à la Sporotrichose dont je venais de lire les observations dans nos bulletins, et j'essayai l'iodure. Six semaines après, il sortait 
suffi d'en appeler de médecins insuffisamment instruits à des praticiens bien informés, pour que, les choses étant mises au point, intérêts des malades fussent bien servis ${ }^{1}$ ) ... .

-Tout médecin qui, au premier jour de sa pratique, ne sait pas diagnostiquer la syphilis, est un malhonnête homme, * aimait à répéter Hardy. "Que de fois je rous ai montré les préjudices individuels, familiaux ou sociaux, causés par des médecins qui, en matière d'affections syphilitiques que nous n'avions pas difficulté de diagnostiquer dans nos salles, étaient coupables, du fait de leur insuffisance en Syphiligraphie. L'idée qu'exprimait arec tant de vigueur mon maître $\mathrm{Hardy}$, chez qui la conscience fut toujours égale à la science, on peut la reprendre à propos de toutes les affections, entre autres, à propos des infections mycosiques. ${ }^{2}$ )

L'intérêt doctrinal des Sporotrichoses n'est pas moins grand que leur intérêt pratique.

L'étude des Sporotrichoses a rénové la Pathologie générale des mycoses. On croyait autrefois que les mycoses formaient un groupe à part et, malgré les travanx de Roger sur le muguet on avait des idées si incomplètes sur ces infections mycosiques qu'on croyait pouvoir les opposer aux infections bactériennes.

guéri. - Le second entra dans mon service l'hiver dernier et me dit qu'on lui avait fait des piqûres de mercure sans résultat. J'en conclus naturellement que son médecin le considérait comme syphilitique. Je crus à la Sporotrichose, je lui appliquai le même traitement ioduré qui eut le même succès.

Si je vous ai fait part de ces deux faits . . . . e'est parce que ces deux malades doivent certainement la vie à votre belle découverte.

1) Les trois cas cubains que Duque a rapportés en 1909 sont de nouveaux témoins des désastres irréparables que peut déterminer l'ignorauce des Sporotrichoses. Malgré les amputations que les malades avaient subies, la mycose méconnue continuait d'évolner et ia guérison ne survint que lorsque le diagnostic exact de Sporotrichose fut posé et indiqua l'emploi de la médication iodurée.

2) Voir notre chapître: Infections mycosiques in $A$. Gilbert et L. Thoinot, Noureau Traitéde Médecine et de Thérapeutique. Fase. IV. 1910, p. 371 et 373. 
Nos recherches celles de Widal et Abrami (1908), de Bruno Bloch (1909) ont donné à la question des mycoses un essor nouveau. Il est aujourd'hui démontré que, loin d'opposer les mycoses aux injections bactériennes, il faut au contraire les en rapprocher étroitement, car il n'existe entre ces deux séries de maladies que des différences de degré ou de détails.

Dans cette démonstration l'étude de la Sporotrichose de de Beurmann a eu la part la plus importante et la plus décisive. Elle a montré que le polymorphisme anatomoclinique des mycoses peut être aussi grand que celui des infections bactériennes, qu'un même parasite, le Sporotrichum Beurmauni peut se localiser sur tous les tissus et déterminer les formes cliniques les plus diverses. Elle a prouvé que l'érolution et le pronostic des mycoses peut être aussi variables que ceux des infections bactériennes puisque le Sporotrichum Beurmanni, qui le plus souvent provoque une maladie chronique et bénigne aux lésions indolentes et froides, peut aussi donner des abcès chauds, des infections fóbriles et peut même entraîner la mort.

Elle a montré que le polymorphisme histologique des réactions des tissus en présence des champignons pathogènes est au moins aussi grand que celui des infections bactériennes. Un même parasite, le Sporotrichum Beur manni, produit les réactions les plus diverses, depuis les infiltrats cellulaires jusqu'aux scléroses, depuis l'hypertrophie cellulaire jusqu'aux dégénérescences, depuis la congestion jusqu'à l'abcès. Dans une même lésion, le mycome nodulaire à trois zones, le Sporotrichum, réunit trois réactions différentes: au centre, l'abcès polynucléaire et macrophagique des suppurations cocciennes et ecthymateuses; à la partie moyenne, les cellules géantes, les follicules et la dégénérescence épithélioïde de la tuberculose; à la périphérie, l'infiltrat lympho-conjonctif basophile et plasmatique, les vascularites de la syphilis! L'histologie pathologique de la Sporotrichose rénove l'étude anatomique des maladies nodulaires et des follicules tuberculoïdes. Elle prouve une fois de plus qu'il n'existe pas de lésions spécifiques mais seulement des lésions "spéciales*, caractérisées par tout un ensemble de réactions. 
L'étude de la Sporotrichose éclaire la biologie et la pathogénie des mycoses et montre qu'entre les infections bactériennes et les mycoses, on ne peut relever que des nuances, tenant uniquement à des inégalités d'adaptation à la vie parasitaire. Elle permet de retrouver dans les mycoses toutes les particularités découvertes dans les grandes infections bactériennes: saprophytisme des parasites dans la nature, chez les animaux et chez l'homme; inoculation cutanée ou muqueuse; importance des contaminations digestives; passage des germes à travers l'épiderme ou l'épithélium muqueux intacts; complexité des causes d'infection: diminution de résistance du terrain, augmentation de virulence du germe ou adaptation du germe au terrain, sensibilisation du terrain par les sécrétions du parasite saprophyte, ou adaptation du terrain au germe; dissémination vasculaire sanguine septicémique ou lymphatique; production d'une forme d'adaptation bacilliforme à la vie parasitaire différente de la forme filamenteuse et sporulée des cultures in vitro; action non seulement mécanique mais toxinique multiple du parasite, prépondérance des toxines locales adipocireuses (chloroformo-sporotrichosine, éthéro-sporotrichosine, etc.) et des toxines solubilisables (alcoolo-toxine, extraits acides, basiques, etc.) dont les actions peuvent être dissociées; complexité de la lutte de l'organisme contre le parasite: macrophagie, sécrétions, etc.; persistance après la guérison de champignons saprophytes dans le tube digestif, donc existence de porteurs de germes ...

L'étude de la Sporotrichose a montré qu'une infection mycosique peut, au même titre qu'une bacilléme, déterminer dans l'organisme humain des réactions humorales multiples: production d'agglutinine et d'anticorps révélés par la réaction de fixation; formation de précipitine; sensjbia lisation et anaphylaxie, et chez les animaux, immunisation. Elle a mis en évidence l'importance de réactions de groupe: co-agglutinations et co-fixations, qui permirent à Widal et Abrami d'instituer un séro-diagnostic de l'actinomycose; co-sensibilations, qui ont prévoir l'importance pathogénique de polymycoses. 
de Beurmann et Gougerot.

La Sporotrichose, dans presque tous les chapitres de la mycologie pathologique, a donc eu un rôle d'Initiatrice; elle a fait connaître des faits nouveaux du plus haut intérêt et a mis en lumière la valeur des observations anciennes; enfin elle a apporté à la pathologie générale une contribution des plus importantes.

Non seulement la Sporotrichose a permis de renouveler toute la pathologie des mycoses, mais elle a encore été l'occasion de la découverte de mycoses nouvelles.

Autrefois, à l'exception des teignes, les mycoses passaient en Europe pour des curiosités sans intérêt pratique. Les cas d'actinomycose, de blastomycoses ou mieux exascoses, si fréquents au contraire en Amérique, les observations d'aspergillose, étaient des plus rares. On ne citait que quelques faits exceptionnels de mucormycoses et les mycetomes ne semblaient guère exister qu'en pays tropicaux.

Aujourd'hui, grâce à la Sporotrichose, la fréquence et l'importance des mycoses se sont imposées à tous. Des recherches systématiques ont multiplié les cas de Sporotrichose et prouvé qu'à côté d'elle, se groupent d'autres mycoses insoupçonnées que la connaissance des sporotrichoses a seule permis de découvrir.

C'est en la recherchant que Ravaut et Pinoy ont découvert une nouvelle Discomycose, due au Discomyces Thibiergi; que Gougerot et Caraven ont individualisé une nouvelle mycose, l'Hemisporose, due à l'Hemispora stellata; que de Beurmann, Gougerot et Vaucher ont isolé une Oïdiomycose, due à un parasite nouveau, l'Oỉium cutaneum; que Gougerot, dans les préparations de Carougea u a décélé avec cet auteur un des parasites des nodosités juxta-articulaires et l'a dénommé $\mathrm{D}$ is com y ces Carougei, que Balzer, Burnier et Gougerot ont trouré un cas de parendomycose gommeuse, due à un parasite nouveau le Parendomyces Balzeri, et cultivé le Mycoderma pulmoneum dans des lésions dermiques, nouvel exemple de Dermatomycose verruqueuse et végétante. C'est encore en 
recherchant la Sporotrichose que Bruno Bloch, à Bâle, a découvert un parasite nouveau, dénommé par Matruchot Mastigocladium Blochi (premier exemple de cladiose humaine), que Potron et Noisette, près de Nancy, ont cultivé un nouveau champignon, appelé par Vuillemin, Acremonium Potroni (premier exemple d'acrémonioses) les faits se multiplient et nous arons connaissance de plusieurs séries de recherches encore inédites, poursuivies en France et à l'étranger, dont le point de départ a toujours été la. Sporotrichose.

- En même temps donc que nos connaissances générales se précisent sur les infections mycosiques, leur nombre et leur fréquence augmentent, leur importance se montre de plus en plus grande. Grâce à la Sporotrichose, un chapitre nouveau, déjà riche de faits, est ouvert et les mycoses, qui avaient été si longtemps négligées, prennent enfin en pathologie la place qui leur est due.* On découvre un monde nouvean, hier à peine soupçonné, et qui commence seulement à être exploré.

L'histoire des Sporotrichoses, née de la volonté d'élucider la pathogénie de certaines lésions de nature douteuse, est donc dès maintenant aussi avancée que celle des maladies infectieuses les plus anciennement connues. Les Sporotrichoses, à peine soupçonnées il y a quelques ans, ont pris une place des plus importantes dans la grande pathologie. Elles intéressent non seulement les dermatologistes qui ont su les distinguer des affections avec lesquelles elles étaient confondues, mais encore les médecins, les chirurgiens, les laryngologistes, les ophthalmologistes, etc. qui peuvent chaque jour rencontrer leurs manifestations. Leur étude, rapidement conduite, a bénéficié de toutes les ressources et de toutes les découvertes de la clinique et du laboratoire et à peine achevée, elle a déjà pu ajouter aux faits anciens des dounées nouvelles et apporter à la pathologie générale une intéressante contribution. 
C'est done arec satisfaction que nous pouvons mesurer le chemin parcouru en si peu de temps, et constater que l'étude de la dermatologie, loin de rétrécir l'horizon du médecin, peut ouvrir aux études médicales des voies nouvelles. 